\title{
Fatty Dihydropyridines With Anti-Hypertensive and Cardioprotective Potential During Ischemia and Reperfusion
}

eduarda Santa-Helena ( $\nabla$ eduarda.shelena@hotmail.com )

FURG: Universidade Federal do Rio Grande https://orcid.org/0000-0003-3286-8771

Joaquim de Paula Ribeiro

FURG: Universidade Federal do Rio Grande

Carolina Rosa Gioda

FURG: Universidade Federal do Rio Grande

Diego da Costa Cabrera

FURG: Universidade Federal do Rio Grande

Marcelo G. Montes D'Oca

FURG: Universidade Federal do Rio Grande

Luiz Eduardo Maia Nery

FURG: Universidade Federal do Rio Grande

Carla Amorim Neves Gonçalves

FURG: Universidade Federal do Rio Grande

\section{Research Article}

Keywords: hypertension, ischemia, new fatty dihydropyridines, oxidative stress, reperfusion

Posted Date: June 16th, 2021

DOl: https://doi.org/10.21203/rs.3.rs-611018/v1

License: (9) (i) This work is licensed under a Creative Commons Attribution 4.0 International License. Read Full License 


\section{Abstract}

In this study, three fatty dihydropyridines, were tested for their anti-hypertensive and cardioprotective properties. Dihydropyridines 2c, 8c, and 9a contain the oleic chain and the nitro unit, the oleic chain and the chlorine unit, and the palmitic chain and the chlorine unit, respectively. For the experiments, animals were treated with $\mathrm{N}(\omega)$-nitro-L-arginine methyl ester to induce hypertension and after treated with the new dihydropyridine compounds and the standard drug nifedipine. Then, the heart was removed and subjected to global ischemia and reperfusion. Analyses of cardiac parameters were performed to monitor cardiac functionality; lactate dehydrogenase values were quantified in perfusates. After ischemia and reperfusion were performed, analyses to check the oxidative status and lipid damage. The results of the present study suggest that the new fatty DHPs have anti-hypertensive effects offering protection against ischemia to the heart of rats, accomplished by increasing antioxidants that defend and prevent the decline in cardiac function.

\section{Key Points}

New fatty dihydropyridines with a cardioprotective effect.

Dihydropyridines with antihypertensive and antioxidant potential.

New dihydropyridines attenuate induced hypertension in Wistar rats.

\section{Introduction}

Acute myocardial infarction (AMI) is one of the most common health problems in the world, and one of the main causes of morbidity and mortality [1], as a consequence of ischemia and reperfusion (I/R). Ischemia occurs when the arterial flow is insufficient to maintain normal functions, and reperfusion occurs when the ischemic tissue or organ receives blood supply again [2] Ischemia, if not reversed early, significantly compromises the survival of cardiac tissue, worsening the prognosis of affected patients [3]. The majority of mortality occurs even before these patients arrive at the hospital, while those who receive early and specialized treatment have better survival prognoses [3].

Hypertension is one of the biggest risk factors for cardiovascular diseases, such as $\mathrm{I} / \mathrm{R}$, because the pathophysiological mechanisms complex that leads to increased blood pressure can cause damage in different ways, such as endothelial dysfunction, imbalance of oxidative state, arterial remodeling and vascular inflammation $[4,5]$. The strong contraction of cardiac tissue, due to calcium overload, is one of the factors responsible for AMI injury [6]. Research also demonstrates that ischemia and reperfusion generate reactive oxygen species, and other products, that cause oxidative damage to biomolecules, such as lipids, proteins, and DNA, leading to loss of membrane integrity followed by necrosis and cell death [7]. During reperfusion, the restoration of blood flow and oxygen supply triggers an increase in reactive Oxygen species (ROS) generation, which can induce apoptotic and/or necrotic responses in affected cells [8]. The treatment of AMI has focused on reducing the energy consumption of cardiac contractile 
machinery to minimize the damage caused by the low supply of oxygen; however, this intervention has shown to be inefficient in controlling oxidative stress generated by the AMI [9].

New dihydropyridines (DHPs) represent an interesting alternative as a pharmaceutical strategy, in search of new drugs with different activities, good safety profiles, cost, and efficiency. The hybridization process of heterocyclics to fatty molecules demonstrated essential importance for biological activity, probably because it facilitates the permeability of these new molecules $[10,11,12]$. Calcium channel blockers have several characteristics that may be related to myocardial protection during $\mathrm{I} / \mathrm{R}$ decreasing oxygen demand due to reduce heart rate and myocardial contractility [13]. A direct protective effect can also be produced by preventing the entry of calcium into the cardiac cell to avoid overload induced by ischemia $[13,14]$. DHPs are a class of calcium channel blockers and are known to protect the heart from ventricular ischemia and arrhythmias, and are currently used to treat hypertension $[15,16]$.

Electrophysiologic studies show that calcium channel antagonists such as DHPs have their most effective action on L-type calcium channels, which are abundant in cardiac musculature and the vascular smooth muscle, reducing the passage of calcium ion with a consequent reduction in vascular tone, and for this reason, it is also used as an anti-hypertensive agent [16]. As an adverse effect, these blockers can lead to excessive vasodilation, cardiac depression, or a prominent increase in sympathetic activity [16].

New fatty DHPs (Fig. 1), with the addition of fatty side chains (oleic $2 \mathrm{c}$ and $8 \mathrm{c}$, or palmitic 9a) and functional groups chlorine (9a and $8 \mathrm{c}$ ) or nitrogen dioxide (2c), have been evaluated in vitro tests and cell culture of cardioblasts $[12,17,18]$. These results [18] demonstrated that several synthesized fatty DHPs improved antioxidant potential when compared to standard pharmaceutical nifedipine, and tests in cardioblast culture demonstrate that these compounds have cardioprotector effects after ischemia and reperfusion $[12,17]$. In a current study by Santa-Helena et al. [19], it has been shown that these fatty DHPs continue to interact with calcium channels, and in addition, these molecules are non-toxic during and after 56 days of treatment. Other dihydropyridine derivatives have been proven to protect the heart from ischemic injury and atherosclerosis [20], due to the capacity to inhibit L-type calcium channel and differentiated cardiac depressive action [21].

Cardiac injury caused by $\mathrm{l} / \mathrm{R}$ can be protected by ischemic preconditioning, or by the use of exogenous cardioprotective agents. Bearing in mind that ischemic preconditioning is hardly feasible in clinical practice, the attention of the scientific public focuses on pharmacological and non-pharmacological methods that would be used before coronary occlusion to reduce the size of the AMI [22]. The present study sought to elucidate whether previous treatment with these three news DHPs in pharmacologically hypertensive rats can mitigate the prevention of cardiac damage caused by ischemia and reperfusion.

\section{Material And Methods}

\subsection{Animals}


The research protocol was approved by the Animal Care and Ethical Use Committee of the Federal University of Rio Grande (P003/2017), RS, Brazil. Forty-two male Wistar rats (weighing $250-400 \mathrm{~g}$ ) were obtained from the Central Animal House of the Federal University of Rio Grande do Sul, RS, Brazil. They were maintained on a $12 \mathrm{~h}$ light / $12 \mathrm{~h}$ dark cycle in constant temperature $22 \pm 2{ }^{\circ} \mathrm{C}$ and received commercial rodent food ( $25 \mathrm{~g} /$ animal/day) and water ad libitum.

\subsection{Pharmacological induction of hypertension and treatments}

Hypertension was induced by the administration of L-NAME (a non-specific nitric oxide inhibitor) (10 $\mathrm{mg} / \mathrm{kg} /$ day) by gavage for eight weeks, except for the control group. The animals were divided randomly into seven groups $(n=6)$, during the last four weeks of treatment with L-NAME. The new fatty dihydropyridines and nifedipine were also administered by gavage. The groups were subdivided into control and group I/R that received a solution of the vehicle (DMSO 1\%, $1 \mathrm{~mL} / 400 \mathrm{~g}$ of weight) for 8 weeks; Group high blood pressure (HBP + l/R) received pretreatment with L-NAME (10 mg/kg/day); Group nifedipine and L-NAME (HBP + nifedipine $+\mathrm{I} / \mathrm{R})$ received at the same time pretreatment with L-NAME (10 $\mathrm{mg} / \mathrm{kg} /$ day $)$ and nifedipine $(0.42 \mathrm{mg} / \mathrm{kg} /$ day $)$. The remaining groups received pretreatment with a combination of L-NAME $(10 \mathrm{mg} / \mathrm{kg} / \mathrm{day})$ and one of the new compounds: $2 \mathrm{c}(\mathrm{HBP}+2 \mathrm{c}+\mathrm{l} / \mathrm{R}), 8 \mathrm{c}(\mathrm{HBP}+$ $8 c+\mathrm{I} / \mathrm{R})$, and $9 \mathrm{a}(\mathrm{HBP}+9 \mathrm{a}+\mathrm{I} / \mathrm{R})$ all at a concentration of $0.42 \mathrm{mg} / \mathrm{kg} /$ day (same concentration used by Santa-Helena et al. [19]. The experiments with isolated hearts were performed $24 \mathrm{~h}$ after the last administration of drugs using a retrograde perfusion system for all groups with exception of the control group, as described in 2.6 .

\subsection{Fatty 2,4-dihydropyridine synthesis}

The synthesis of fatty 2,4-Dihydropyridines was realized according to previous work [18] (Figure 1). Initially the oleyl and stearic fatty $\beta$-ketoesters, were synthesized via transesterification of palmitic (C16:0) or stearic (C18:0) fatty alcohols, respectively. Next, the compounds were employed as fatty 1,3dicarbonnyl compounds in the synthesis of fatty DHPs according to procedure: In a round bottom flask equipped with a reflux condenser were added, $2 \mathrm{mmol}$ of oleyl or stearic fatty $\beta$-ketoesters, $1 \mathrm{mmol}$ of respectively aromatic aldehydes (2-nitro-, 2-chloro or 4 chlorobenzaldehydes), 3mmol of ammonium acetate and $0.30 \mathrm{mmol}$ of sulfamic acid as a catalyst in the presence of $5 \mathrm{~mL}$ methanol. The reaction mixture was stirred constantly at reflux for $24 \mathrm{~h}$. Afterwards, the crude mixture was cooled to ambient temperature, concentrated under vacuum, and purified by column chromatography with gradient elution of hexane: ethyl acetate to afford the hybrid fatty DHP.

Di((Z)-octadec-9-en-1-yl)2,6-dimethyl-4-(2-nitrophenyl)-1,4-dihydropyridine-3,5-dicarboxylate (2c) Yield: 55\%; M.W $818.6 \mathrm{gmol}^{-1}$; oil; ${ }^{1} \mathrm{H}$ NMR $\left(400 \mathrm{MHz}, \mathrm{CDCl}_{3}\right): \delta 0.90(\mathrm{t}, 6 \mathrm{H}, \mathrm{J}=6.6 \mathrm{~Hz}) ; 1.28(\mathrm{~m}, 44 \mathrm{H}) ; 1.55$ (m, $4 \mathrm{H}) ; 2.03(\mathrm{~m}, 8 \mathrm{H}) ; 2.34(\mathrm{~s}, 6 \mathrm{H}) ; 4.01(\mathrm{~m}, 4 \mathrm{H}) ; 5.36(\mathrm{~m}, 4 \mathrm{H}) ; 5.72(\mathrm{~s}, 1 \mathrm{H}) ; 5.84(\mathrm{~s}, \mathrm{H}) ; 7.23-7.74(\mathrm{~m}$,

$4 \mathrm{H}) ;{ }^{13} \mathrm{C}$ NMR (100MHz, $\mathrm{CDCl}_{3}$ ): 14.1 (2C); 19.7 (2C); 22.7 (2C); 25.9 (2C); 27.2 (2C); 28.5-29.8 (20C);

31.9 (2C); 34.8; 64.3 (2C); 104.0 (2C); 124.0; 126.9; 129.8 (2C); 129.9 (2C); 131.3; 132.6; 142.5; 144.4 (2C); 
147.9; 167.3 (2C). IR (film, $\left.v_{\max } \mathrm{cm}^{-1}\right): 772,1214,1524,1696,2845,2924,3010,3360$.

Di((Z)-octadec-9-en-1-yl) 4-(2-chlorophenyl)-2,6-dimethyl-1,4-dihydropyridine-3,5-dicarboxylate (8c) Yield: 71\%; M.W 807.6gmol-1; oil; $\left.{ }^{1} \mathrm{H} \mathrm{NMR} \mathrm{(400MHz,} \mathrm{CDCl}_{3}\right)$ : $\delta 0.90$ (t, $\left.6 \mathrm{H}, \mathrm{J}=6.5 \mathrm{~Hz}\right) ; 1.29(\mathrm{~m}, 44 \mathrm{H}) ; 1.60(\mathrm{~m}, 4 \mathrm{H})$; $2.04(\mathrm{~m}, 8 \mathrm{H}) ; 2.33(\mathrm{~s}, 6 \mathrm{H}) ; 4.04(\mathrm{t}, 4 \mathrm{H}, \mathrm{J}=6.75 \mathrm{~Hz}) ; 5.37(\mathrm{~m}, 4 \mathrm{H}) ; 5.40(\mathrm{~s}, 1 \mathrm{H}) ; 5.66(\mathrm{~s}, \mathrm{H}) ; 7.03-7.41(\mathrm{~m}, 4 \mathrm{H})$; ${ }^{13} \mathrm{C} \mathrm{NMR}\left(100 \mathrm{MHz}, \mathrm{CDCl}_{3}\right)$ : 14.1 (2C); 19.6 (2C); 22.7 (2C); 26.0 (2C); 27.2-29.8 (20C); 31.9(2C); 32.6 (2C); $37.6 ; 64.1$ (2C); 103.9 (2C) ; 126.6; 127.2; 129.4; 129.8 (2C); 129.9 (2C); 131.5; 132.6; 143.8 (2C); 145.5; 167.7 (2C); IV (film, $\left.v_{\max } \mathrm{cm}^{-1}\right)$ : 796, 1115, 1465, 1676, 2845, 2918, 3003, 3333.

Dihexadecyl4-(4-chlorophenyl)-2,6-dimethyl-1,4-dihydropyridine-3,5-dicarboxylate (9a) Yield: 89\%; M.W 755.6gmol ${ }^{-1}$; M.P 57-58 ${ }^{\circ} \mathrm{C}$; solid; ${ }^{1} \mathrm{H} \mathrm{NMR}\left(400 \mathrm{MHz}, \mathrm{CDCl}_{3}\right): \delta 0.90(\mathrm{t}, 6 \mathrm{H}, \mathrm{J}=6.7 \mathrm{~Hz}) ; 1.28(\mathrm{~m}, 52 \mathrm{H}) ; 1.60$ $(\mathrm{m}, 4 \mathrm{H}) ; 2.35(\mathrm{~s}, 6 \mathrm{H}) ; 4.04(\mathrm{~m}, 4 \mathrm{H}) ; 4.98(\mathrm{~s}, 1 \mathrm{H}) ; 5.67(\mathrm{~s}, \mathrm{H}) ; 7.17-7.24(\mathrm{~m}, 4 \mathrm{H}) ;{ }^{13} \mathrm{C} \mathrm{NMR}(100 \mathrm{MHz}$,

$\left.\mathrm{CDCl}_{3}\right): 14.1$ (2C); 19.6 (2C); 22.7 (2C); 26.0 (2C); 28.7-29.7 (22C); 31.9 (2C); 39.2; 64.1 (2C); 103.9 (2C);

127.9 (2C); 129.4 (2C); 131.7; 144.0 (2C); 146.2; 167.5 (2C); IR (film, $\left.v_{\max } \mathrm{cm}^{-1}\right)$ : 745, 1267, 1465, 1696, $2851,2918,3069,3340$.

\subsection{Blood pressure measurement}

Blood pressure was verified by tail-cuff plethysmography using a Non-Invasive Blood Pressure System (LE5001, Panlab Harvard Apparatus). The rats were placed in a restrainer of the appropriate size to balance for a few minutes before checking systolic and diastolic blood pressure, and heart rate. Each animal was adapted to blood pressure and heart rate measurements for three weeks before the start of the experiment. These parameters were measured for each animal before the start of treatment and weekly thereafter. Three consecutive checks were performed, and the averages were calculated for each parameter.

\subsection{Ischemia and reperfusion protocol}

The animals were heparinized (1000 IU) intraperitoneally and after 10 minutes euthanized. After thoracotomy, the inferior cava vena was sectioned to minimize venous return, and the pulmonary veins and aorta were then cut, and the heart was removed and placed in a cold solution (Krebs-Henseleit). Shortly after cannulation ( $18 \mathrm{G}$ cannula), the heart was perfused with cooled Krebs-Henseleit with the constant pressure of $90 \mathrm{mmHg}$ at $37 \pm 1^{\circ} \mathrm{C}$. The heart-nourishing solution was prepared following the concentrations proposed by [60]. Thus producing non-recirculating Krebs-Henseleit solution with $\mathrm{pH} 7.4$ (120 mM NaCl, $5.9 \mathrm{mM} \mathrm{KCl}, 1.2 \mathrm{mM} \mathrm{MgSO} 4,1.75 \mathrm{mM} \mathrm{CaCl} 2,25 \mathrm{NaHCO}$, and $11 \mathrm{mM}$ glucose) was filtered at $0.25 \mu \mathrm{m}$ and posteriorly saturated with carbogen ( $95 \%$ oxygen and $5 \%$ carbon dioxide).

After cannulation, each heart underwent the same procedure, except for the control group. The hearts were stabilized for 10 minutes. After the baseline time (10 minutes), the global ischemia was induced for 
20 minutes and the reperfusion time was reestablished for 40 minutes (Figure 2). During the experiments, $2 \mathrm{~mL}$ of perfusate were collected at 15 and 80 minutes, in addition to photographing the heart every 10 minutes.

\subsection{Measurement of cardiac parameters}

\section{Pressure apparatus mounting}

This procedure was performed according to Jia et al. [26], which consists in the measurement and monitoring of left ventricular developed pressure (LVDP) through a latex balloon containing ultrapure water (pressure of $10 \mathrm{mmHg}$ ) and connected to a pressure transducer and an amplifier and data collected in real-time through software (ANCAD).

\subsection{Differential pressure $( \pm \mathrm{dP} / \mathrm{dT})$}

To calculate the first derivative of ventricular pressure over time, $\pm \mathrm{dP} / \mathrm{dT}$ was obtained following the calculations of Migliore [24], which considers the rate of change of inclination of a signal over a period, associated with the method of Sarazan et al. [25] for the up-to-date integration of data collection software for converting the signal into mathematical data.

\subsection{Mean arterial pressure (MAP)}

Digitized systolic pressure (SP) and diastolic pressure (DP) data were used with the following calculation $\mathrm{MAP}=\mathrm{DP}+0.333(\Delta \mathrm{P})$, with $\Delta \mathrm{P}=\mathrm{DP}-\mathrm{SP}$ and 0.333 is $1 / 3$ of the cardiac cycle, assuming that systole occupies $2 / 3$ according to Razminia et al. [26].

\subsection{Caliber image in situ evaluation}

The left anterior descending coronary artery was constantly monitored in situ using a portable digital microscope (GL1600x), placed next to the heart, with a focus plane on the artery that nourishes the interventricular septum and the cardiac apex. With ambient light, 40-50X lens, 1024x768 pixel image, and 30,000 frame rates were obtained intact and functioning heart surface images by adapting the method of Chen et al. [27]. Images were recorded every 10 minutes and then analyzed using Image J software.

\subsection{Biochemical Analyses}

\section{Total antioxidant capacity against peroxyl radical (ACAP)}

After experimental procedures with the isolated heart were completed, the heart was homogenized and centrifuged $(10,000 \times \mathrm{g})$ at $4^{\circ} \mathrm{C}$ for 20 minutes. Aliquots of $15 \mu \mathrm{L}$ of each sample (three replicates) were placed into a plate with $120 \mu \mathrm{L}$ of buffer (Hepes, $\left.\mathrm{KCl}, \mathrm{MgCl}_{2}\right), 10 \mu \mathrm{l}$ of ABAP ([2,2'-Azobis (2 methylpropionamidine) dihydrochloride]), and $20 \mu \mathrm{l}$ of $\mathrm{H}_{2}$ DCF-DA (2',7'-dichlorodihydrofluorescein diacetate). The fluorescence intensity was determined over 60 minutes at $37^{\circ} \mathrm{C}$ using a fluorometer (FilterMax F5, molecular device) at excitation and emission wavelengths of 450 and $535 \mathrm{~nm}$, respectively. 
The antioxidant capacity was expressed in terms of the fluorescence area, after fitting fluorescence data to a second order polynomial and integrating between 0 and $60 \mathrm{~min}$ to obtain its area, being the inverse of the area difference in fluorescence with and without ABAP [28].

\subsection{Lipid peroxidation (LPO)}

Thiobarbituric acid reactive substances (TBARS) were measured through malondialdehyde concentration in samples by measuring fluorescence at 520 and $595 \mathrm{~nm}$ for excitation and emission wavelengths, respectively. TBARS levels were expressed as malondialdehyde/mg of tissue, using tetramethoxypropane (TMP, Acros Organics) as a standard [29].

\subsection{Catalase Activity}

Catalase activity occurred by analyzing the decomposition of $\mathrm{H}_{2} \mathrm{O}_{2}$ as a function of time. The reaction was performed in triplicate adding $\mathrm{H}_{2} \mathrm{O}_{2}(0.3 \mathrm{M}), 2 \mathrm{~mL}$ potassium phosphate buffer $(\mathrm{KPB}, 50 \mathrm{mM})$ in pH 7.0 at $25^{\circ} \mathrm{C}$, according to Nelson and Kiesow [30]. During $1 \mathrm{~min}$, the decomposition of $\mathrm{H}_{2} \mathrm{O}_{2}$ by catalase was evaluated at $240 \mathrm{~nm}$. Catalase activity is expressed as $\Delta \mathrm{Abs} / \mathrm{min} / \mathrm{milligram}$ of protein.

\subsection{Lactate dehydrogenase (LDH) activity}

LDH activity was measured in heart perfusate samples collected from the coronary, during the I/R protocol according to the manufacturer's recommendations (LDH Liquiform - Labtest, Brazil). This method was performed using a spectrophotometer (800 ELX Universal Microplate Reader, Bio-TEK) and evaluated the decreasing absorption of $\mathrm{NADH}$ at $340 \mathrm{~nm}$ for $3 \mathrm{~min}$ at $37^{\circ} \mathrm{C}$.

\subsection{Statistical analysis}

Data were quantified as the mean and standard error of mean (SEM) and statistical methods to assess the degree of significance were utilized [31]. For cardiac contractility and arterial caliber data (HR, LVDP, \pm $\mathrm{dP} / \mathrm{dT}$, MAP and vasoconstriction) two-way ANOVA analysis of variance followed by the Newmann Kells posttest was performed. In the biochemical tests, one-way ANOVA followed by the Newmann Kells posttest was completed. The level of statistical significance was set at $95 \%$.

\section{Results}

In the first phase of our investigation, the focus was placed on the understanding of the effects pharmacological preconditioning of new fatty dihydropyridines and its cardioprotection in I/R concerning cardiac dynamic parameters, which are indicators of heart function. During the second phase of our research was approached the effects of preconditioning with new drugs on antioxidant capacity and lipid damage, oxidative stress markers, after an I/R event.

\subsection{Result of cardiac parameters}


The induction of high arterial pressure in animals was performed with the use of L-NAME (10 $\mathrm{mg} / \mathrm{kg} /$ day). In Figure 3A, a significant increase in systolic blood pressure (occurred on the $14^{\text {th }}$ day) and an increase of diastolic blood pressure were verified on the $21^{\text {st }}$ day (Figure $3 \mathrm{~B}$ ). When comparing the groups that received LNAME (all HBP) with the groups that received saline solution (Control and I/R) ( $p$ $<0.05$ ), we can verify that the treatment to induce hypertension was effective (Figure 3 ). On the $29^{\text {th }}$ day, treatment was started with new fatty dihydropyridines and nifedipine simultaneously. From the $35^{\text {th }}$ day of treatment with DHPs, compounds $\mathbf{2 c}, \mathbf{8 c}, \mathbf{9 a}$, and NIF reduced the systolic blood pressure when compared with the HBP $+1 / R$ group $(p<0.05)$. The diastolic blood pressure shows a reduction with treatments of $\mathbf{9 a}, \mathrm{NIF}$ (day 35 ) and $\mathbf{2 c}$ (day 49$)$ in relation to the HBP group $+\mathrm{I} / \mathrm{R}(\mathrm{p}<0.05)$. These results indicate that the new DHPs, $2 \mathrm{c}$ and $\mathbf{9 a}$, were able to decrease the blood pressure values, both diastolic and systolic, and the new DHP, $\mathbf{8 c}$, reduce the values of systolic pressure only (Figure 3 ). These findings suggest that the effects of these new compounds seem to have maintained the characteristic blocking of calcium channels.

The heart rate during treatment is shown in figure 4. Throughout the experiment (56 days) the heart rate was verified weekly (figure 4). From day 21 L-NAME treatment presents the significant increase $(p<0.05)$ in the treated groups in relation to the control and I/ $\mathrm{R}$ group.

Hemodynamic parameters were evaluated to verify the protection of new fatty DHPs. Heart rate was evaluated in isolated hearts of rats submitted to ischemia and reperfusion and BPM values were determined. All treatments show lower BPM values (Figure 5, $p<0.05$ ) before ischemia concerning the $\mathrm{HBP}+\mathrm{I} / \mathrm{R}$ group. During ischemia, BPM values were decreased significantly for all groups, except for the control group that maintained consistent values. In reperfusion, after 60 minutes, all treatments normalize BPM and show a difference from the HBP + l/R group $(p<0.05)$.

When left ventricle developed pressure (LVDP) was analyzed (Figure 6), pretreatment with compounds significantly improved LVDP values during reperfusion, while the untreated groups present lower values. At 60 minutes after ischemia, the groups $\mathrm{HBP}+2 \mathrm{c}+\mathrm{l} / \mathrm{R}$, and HBP $+\mathrm{NIF}+\mathrm{l} / \mathrm{R}$ are not statistically different from the control group $(p>0.05)$, and the groups HBP $+2 c+I / R$ and HBP $+N I F+I / R$ are different $(p<$ 0.05) from the HBP + I/R group (Figure 5).

Evaluating the left ventricular contraction speed, only treatments with compounds $\mathbf{8 c}$ and NIF can normalize left ventricular contraction time at the end of reperfusion (Figure 7).

When we analyze the differential pressure, meaning the ventricular contraction speed $( \pm d P / d T)$, at the end of I/R, after 80 minutes of the experiment, the group HBP $+8 \mathrm{c}+\mathrm{I} / \mathrm{R}$ and HBP $+\mathrm{NIF}+\mathrm{I} / \mathrm{R}$ differ from the HBP + I/R group $(p<0.05)$. All other groups are different from the control $(p<0.05)$ at all times of reperfusion (Figure 7). Only treatments with compounds $\mathbf{8 c}$ and NIF can normalize the left ventricular contraction time at the end of reperfusion.

Mean arterial pressure values for all treatments $(2 \mathrm{c}, \mathbf{8 c}, \mathbf{9 a}$ and NIF) are not different from the control group $(p>0.05)$ and they are different $(p<0.05)$ from the HBP + I/R group in the time 60 minutes 
(reperfusion) (Figure 8).

The only treatment that allowed an increase in vasodilation during the reperfusion period was $\mathbf{2} \mathbf{c}$ when compared to the HBP + I/R group $(p<0.05)$ (Figure 9$)$.

\subsection{Biochemical Analyses}

Biochemical data demonstrate that treatment with compound $2 c(H B P+2 c+1 / R)$ showed a decrease in LDH values concerning groups I/R and HBP $+\mathrm{I} / \mathrm{R}(\mathrm{p}<0.05)$ (Figure 10), suggesting a cardioprotective effect of this compound.

The analysis of antioxidant capacity showed that the ischemia reperfusion protocol decreased the values of the total antioxidant capacity (Figure 11) and that the treatments with compounds $2 \mathrm{c}, \mathbf{8 c}, \mathbf{9 a}$, and NIF, showing none differences in relation to group HBP $+\mathrm{I} / \mathrm{R}(\mathrm{p}>0.05)$ also show no differences in relation to the control group $(p>0.05)$, except for $8 \mathrm{C}$ group that was lower.

The lipid peroxidation (LPO) values (Figure 13) demonstrate that treatment with compounds $\mathbf{2} \mathbf{c}$ and 9a seems to decrease lipid damage, presenting results not different $(p>0.05)$ to the control group, but also not different from the group HBP $+\mathrm{I} / \mathrm{R}(\mathrm{p}>0.05)$.

\section{Discussion}

The study of the isolated heart is used in several types of tests being extremely useful in the translational evaluation of these pharmacological tests [32,33]. According to Tong et al. [34], heart retrograde perfusion models are ex vivo methods of clinical relevance for the study of myocardial infarction to evaluate function and injury.

The ability of DHPs to block calcium channels is linked to the heterocyclic ring $[35,36]$ and this structure has not been altered in the new compounds studied here, which strengthens our suggestion that these compounds continue to bind and inhibit calcium channels. The fact that DHPs prevent the increase of BPM when compared to the HBP + I/R (baseline) (Figure 5) group may indicate a benefit of this treatment. Undoubtedly, the restoration of normal blood flow to the ischemic heart leads to a lower mortality rate of ischemic patients $[7,37]$, however, reperfusion alone can cause a sequence of harmful events, including arrhythmias (particularly), microvascular injury, myocardial dysfunction, myocardial stunning, and finally death [38], showing once again the importance of establishing reperfusion without increasing BPM.

These results are in accordance with an experimental study in isolated hearts [39], which demonstrated that previous treatment with nifedipine induces preconditioning, as shown by the improvement in left ventricular pressure after ischemia. These findings support our results, considering that NIF and $2 c$ present values of PDVE, after 60 minutes, not different from the control group ( $p>0.05)$. In addition, compounds $\mathbf{8 c}$ and $\mathbf{9 a}$ are different from group HBP $+\mathrm{l} / \mathrm{R}(\mathrm{p}<0.05)$, which already suggests an improvement in LVDP after ischemia. The decrease in left ventricular pressure values demonstrates a 
clear impairment in left ventricular function, caused by

pressure overload confirming this increase in blood pressure values in untreated groups (Figure 6).

The reduction in LVDP and $\pm \mathrm{dP} / \mathrm{dT}$ can be used as indicative of I/R injury [40], the lowest values of LVDP were observed in the groups I/R and HBP $+\mathrm{I} / \mathrm{R}$. These results suggest that all compounds demonstrate the ability to reduce I/R injury. Calcium channel antagonists, which can reduce the calcium overload induced by myocardial ischemia, can protect cardiac tissue from changes in its contractility and ejection strength [41]. To the values of $+\mathrm{dP} / \mathrm{dT}$, however, only treatments with compound $\mathbf{8} \mathbf{c}$ and NIF are different from HBP + I/R at the end of reperfusion. Previous studies have emphasized the inhibition of the calcium channels by the use of verapamil in myocardial contraction and the protective effect on excessive calcium overload [42] thus, calcium channel blockers such as dihydropiridines can reduce the size of the ischemic lesion of the myocardium through inhibition of calcium channels, improving the ejection strength and contractility [43].

The impact of endothelial dysfunction is important in understanding myocardial I/R injury [44] the values of vasodilation and vasoconstriction were analyzed. The only treatment that allowed an increase in vasodilation during the reperfusion period was $2 c$ when compared to the HBP $+1 / R$ group $(p<0.05)$ (Figure 9). It is important to note that, in Wistar-Kyoto rats, L-NAME has been shown to completely block the relaxation induced by acetylcholine in blood vessels [45], which suggests once again that compound $2 \mathrm{c}$ can block calcium channels of smooth muscle, and cause vasodilation.

Simonovic and Jeremic [46] suggest that preconditioning with calcium channel blockers (verapamil, amlodipine) improved the recovery of contractile function during reperfusion. Pre-conditioning may be involved in this study because it prevents changes in the redox state of cardiac tissue, caused by increased blood pressure. The loss of redox homeostasis results in the activation of pro-inflammatory and profibrotic pathways in the heart, which leads to diastolic dysfunction, probably a result of increased left ventricular diastolic stiffness.

Before ischemia (time $=15$ minutes) perfusate was collected, but the LDH values were undetectable. In cardiac studies, they found that nifedipine reduces leakage of LDH and accumulation of neutrophils after myocardial I/R injury [47]. In this study, we found that only compound $\mathbf{2 c}$ led to a statistically significant decrease in LDH levels, which is the biomarkers of cardiac injuries.

At the early phase of reperfusion free radicals are released. Also, $1 / \mathrm{R}$ will result in a decrease in the antioxidant activity which renders the myocardium extremely vulnerable [48]. Previous findings support that increased lipophilicity can increase the antioxidant potential of DHP [12,17, 18 and 19]. Tanaka et al. [49] demonstrates that amlodipine, a highly lipophilic DHP, reduces oxidative stress. Our previous results also demonstrate that DHPs that received the addition of fatty acids have greater antioxidant potential, in addition to attenuating reactive species in cardioblasts undergoing $\mathrm{I} / \mathrm{R}[12,17,18]$.

Currently, therapies to mitigate the damage caused by I/R are based on reducing the formation of reactive species [50], so the discovery of new compounds that have an antioxidant effect is important to treat this 
pathology. The antioxidant protection under the conditions of oxidative injury is a complex system in which separate antioxidant elements co-operate with each other. The function of one antioxidant often potentiates the effects of another element in the system [51], as observed in the treatment with compound $2 \mathrm{c}$ on catalase activity (Figure 12).

Alam et al. [52] in their study with rats, showed that another dihydropyridine, amlodipine, decreased the levels of LPO in a dose-dependent manner. Literature data suggest that DHPs can inhibit lipid peroxidation accumulation in cardiac membranes by blocking calcium channels [53] but only compounds $\mathbf{2 c}$ and $\mathbf{9 a}$ do not show a statistical difference from the control group..

In the present investigation, the reduced levels of catalase activity observed in ischemic/reperfused untreated hearts were significantly reversed by treatment with compound $\mathbf{2 c}$. This suggest that the intervention assisted the inherent cardiac antioxidant system in combating hydrogen peroxide generated by the I/R episode. The enormous amount of $\mathrm{H}_{2} \mathrm{O}_{2}$ resulting from the I/R cycle could trigger the production of the highly reactive hydroxyl radicals via Fenton reaction involving transition metal ions, like $\mathrm{Fe}^{2+}$ [54]. Such hydroxyl radicals and other resulting reactive species are capable of degrading polyunsaturated lipids, thus forming malondialdehyde. The relatively high degree of membrane peroxidation observed for I/R untreated hearts when compared with that of the non-ischemic and $\mathbf{2 c}$ and 9a treated hearts might be indicative of the protection afforded by the treatment.It is also important to note that the dose administered for all DHPs was $0.42 \mathrm{mg} / \mathrm{kg} /$ day. As the molecular weight of the compounds are different (NIF $346.3 \mathrm{~g} / \mathrm{mol} ; \mathbf{2 c} 818.6 \mathrm{~g} / \mathrm{mol} ; \mathbf{8 c} 807.6 \mathrm{~g} / \mathrm{mol}$ and $9 a$ to $755.6 \mathrm{~g} / \mathrm{mol}$ ), this suggests a greater potential for new fatty DHPs.

The literature describes that a substituent at position C2 and C3 of the DHP ring influences its antioxidant activity [55], which is one of the replacement sites for the fatty acids used. The greater lipophilicity of the new DHPs, and their possible binding to a mitochondrial channel, could explain the promising results of the observed ROS reduction seen during the induced I/R. In addition, it is already known that the addition of a halogen, such as chlorine, increases the electron-donating effect of some molecules [56], this addition was carried out in compound $\mathbf{9 c}$, already in compound $\mathbf{2 c}$ and the addition of a $\mathrm{NO}_{2}$ group also affects redox properties [57].

Manidipine is a highly lipophilic calcium antagonist, which guarantees a 24-hour action profile, despite a relatively short plasma half-life due to its high liposolubility, the compound is quickly removed from circulation and binds to plasma membranes continuously binding to calcium channels [58]. By adding lipid chains and observing the results obtained in this work, we can suggest that the new DHPs behave similarly to manidipine, being able to bind the membrane more easily, thus blocking calcium channels more effectively and preventing the accumulation of calcium ions inside the cell. The following mechanism may explain the better performance of the new DHPs when compared to nifedipine. When under conditions of cytosolic calcium overload, calcium can cause mitochondrial damage by triggering the opening of the mitochondrial permeability transition pore, leading to mitochondrial membrane 
permeabilization and generating reactive oxygen species, resulting in mitochondrial dysfunction and cell death [59] and thus generating a change in cardiac functionality.

In conclusion, the present study suggests that new fatty DHPs have an anti-hypertensive and antiarrhythmic effect, in addition to offering protection against I/R injury in the hearts of rats and preventing a decline in cardiac function. The new fatty DHPs, mainly $\mathbf{2} \mathbf{c}$, which had the addition of oleic acid and nitrogen dioxide, could serve as sources of user agents to combat the complications associated with myocardial I/R injury. However, more studies are still needed to elucidate the pharmacodynamics and pharmacokinetics of these new dihydropyridines.

\section{Declarations}

\section{Authors Contributions}

The authors declare that all data were generated in-house and that no paper mill was used.

\section{Compliance with Ethical Standards}

The members of the research team and other collaborators declare no conflict of interest in this research.

This work was carried out with the support of the Higher Education Personnel Improvement Coordination - Brazil (CAPES) - Financing Code 001, and CNPq for financial support.

\section{References}

1. Balla S, Alqahtani F, Alhajji M, Alkhouli M (2020, March) Cardiovascular Outcomes and Rehospitalization Rates in Homeless Patients Admitted With Acute Myocardial Infarction. In Mayo Clinic Proceedings. Elsevier

2. Douzinas EE, Apeiranthitis A (2019) Basic Mechanisms of Ischemia/Reperfusion Injury Leading to Cellular and Tissue Damage: Therapeutic Implications. In: Modulation of Oxidative Stress in Heart Disease. Springer, Singapore, pp 645-670

3. O'Gara PT, Kushner FG, Ascheim DD, Casey DE, Chung MK, De Lemos JA, ... \& Granger CB (2013) 2013 ACCF/AHA guideline for the management of ST-elevation myocardial infarction: a report of the American College of Cardiology Foundation/American Heart Association Task Force on Practice Guidelines. J Am Coll Cardiol 61(4):e78-e140

4. Montezano AC, Dulak-Lis M, Tsiropoulou S, Harvey A, Briones AM, Touyz RM (2015) Oxidative stress and human hypertension: vascular mechanisms, biomarkers, and novel therapies. Can J Cardiol 31(5):631-641

5. Wallert M, Ziegler M, Wang X, Maluenda A, Xu X, Yap ML, ... Zhang J (2019) a-Tocopherol preserves cardiac function by reducing oxidative stress and inflammation in ischemia/reperfusion injury. Redox Biol 26:101292 
6. Rastaldo R, Pagliaro P, Cappello S, Penna C, Mancardi D, Westerhof N, Losano G (2007) Nitric oxide and cardiac function. Life sciences 81(10):779-793

7. Moens AL, Claeys MJ, Timmermans JP, Vrints CJ (2005) Myocardial ischemia/reperfusion-injury, a clinical view on a complex pathophysiological process. Int J Cardiol 100(2):179-190

8. Van Golen RF, van Gulik TM, Heger M (2012) Mechanistic overview of reactive species- induced degradation of the endothelial glycocalyx during hepatic ischemia/reperfusion injury. Free Radic Biol Med 52(8):1382-1402

9. Bainey KR, Armstrong PW (2014) Clinical perspectives on reperfusion injury in acute myocardial infarction. American heart journal 167(5):637-645

10. D'Oca CDRM, Coelho T, Marinho TG, Hack CRL, da Costa Duarte R, da Silva PA, D'Oca MGM (2010) Synthesis and antituberculosis activity of new fatty acid amides. Bioorg Med Chem Lett 20(17):5255-5257

11. Rodrigues MO, Cantos JB, D'Oca CRM, Soares KL, Coelho TS, Piovesan LA, ... \& D'Oca MGM (2013) Synthesis and antimycobacterial activity of isoniazid derivatives from renewable fatty acids. Bioorg Med Chem 21(22):6910-6914

12. Santa-Helena E, da Costa Cabrera D, Teixeira S, Rodrigues J, Castro M, D'Oca MGM, ... \& Gonçalves CAN (2019) New fatty dihydropyridines present cardioprotective potential in H9c2 cardioblasts submitted to simulated ischemia and reperfusion. Biomed Pharmacother 109:1532-1540

13. Katsumata N, Ma X, Higuchi H (2000) Protective effect of diltiazem against ischemia-induced decreases in regional myocardial flow in rat heart. Eur J Pharmacol 398(1):83-91

14. Tamura K, Suzuki Y, Koga T, Akima M, Kato T, Nabata H (1996) Actions of CP-060S on veratridineinduced $\mathrm{Ca} 2+$ overload in cardiomyocytes and mechanical activities in vascular strips. Eur $\mathrm{J}$ Pharmacol 312(2):195-202

15. Triggle DJ (1998) Mechanisms of action of calcium channel antagonists. Calcium antagonists in clinical medicine. Ed. by M. Epstein. Philadelphia, 1-26

16. Godfraind T (2017) Discovery and development of calcium channel blockers. Front Pharmacol 8:286

17. Santa-Helena E, Teixeira S, de Castro MR, da Costa Cabrera D, D'Oca CDRM, D'Oca MGM, ... \& Gonçalves CA N (2017) Protective role of the novel hybrid 3, 5-dipalmitoyl-nifedipine in a cardiomyoblast culture subjected to simulated ischemia/reperfusion. Biomed Pharmacother 92:356-364

18. Cabrera DC, Santa-Helena E, Leal HP, de Moura RR, Nery LEM, Gonçalves CAN, ... \& D'Oca MGM (2019) Synthesis and antioxidant activity of new lipophilic dihydropyridines. Bioorganic chemistry 84:1-16

19. Santa-Helena E, da Costa Cabrera D, D'Oca MGM, Scaini JLR, de Oliveira MWB, Werhli AV, ... \& Nery LEM (2020) Long-chain fatty dihydropyridines: Docking calcium channel studies and antihypertensive activity. Life Sciences, 118210

20. Opie LH, Yusuf S, Kübler W (2000) Status atual de segurança e eficácia de bloqueadores dos canais de cálcio em doenças cardiovasculares: uma análise crítica baseada em 100 estudos. Progresso em 
doenças cardiovasculares 43(2):171-196

21. Triggle DJ (2003) 1, 4-Dihydropyridines as calcium channel ligands and privileged structures. Cell Mol Neurobiol 23(3):293-303

22. Altamirano F, Wang ZVe, Hill JA (2015) Cardioproteção na lesão de isquemia-reperfusão: novos mecanismos e tradução clínica. J Physiol 593(17):3773-3788

23. Jia W, Jian Z, Li J, Luo L, Zhao L, Zhou Y, ... Xiao Y (2016) Upregulated ATF6 contributes to chronic intermittent hypoxia-afforded protection against myocardial ischemia/reperfusion injury. Int J Mol Med 37(5):1199-1208

24. Migliore RA, Adaniya ME, Miramont G, Guerrero FT, Tamagusuku H (2000) Estimación no invasiva de la dP/dt del ventrículo izquierdo.¿ La medición se efectúa durante la contracción isovolumétrica? Archivos de Cardiología de México 70(6):580-588

25. Sarazan RD, Kroehle JP, Main BW (2012) Left ventricular pressure, contractility and dP/dtmax in nonclinical drug safety assessment studies. J Pharmacol Toxicol Methods 66(2):71-78

26. Razminia M, Trivedi A, Molnar J, Elbzour M, Guerrero M, Salem Y, ... Lubell DL (2004) Validation of a new formula for mean arterial pressure calculation: the new formula is superior to the standard formula. Catheterization cardiovascular interventions 63(4):419-425

27. Chen B, Zhang C, Guo A, Song LS (2015) In situ single photon confocal imaging of cardiomyocyte Ttubule system from Langendorff-perfused hearts. Frontiers in physiology 6:134

28. Amado LL, Garcia ML, Ramos PB, Freitas RF, Zafalon B, Ferreira JLR, ... \& Monserrat JM (2009) A method to measure total antioxidant capacity against peroxyl radicals in aquatic organisms: application to evaluate microcystins toxicity. Sci Total Environ 407(6):2115-2123

29. Oakes KD, Van Der Kraak GJ (2003) Utility of the TBARS assay in detecting oxidative stress in white sucker (Catostomus commersoni) populations exposed to pulp mill effluent. Aquat Toxicol 63(4):447-463

30. Nelson DP, Kiesow LA (1972) Enthalpy of decomposition of hydrogen peroxide by catalase at 25C (with molar extinction coefficients of $\mathrm{H} 2 \mathrm{O} 2$ solutions in the UV). NAVAL MEDICAL RESEARCH INST BETHESDA MD

31. Zar JH (1999) Biostatistical analysis 4th ed. New Jersey

32. Britto RM, da Silva-Neto JA, Mesquita TRR, de Vasconcelos CML, de Almeida GKM, de Jesus ICG, ... \& dos Santos FS M (2018) Myrtenol protects against myocardial ischemia- reperfusion injury through antioxidant and anti-apoptotic dependent mechanisms. Food Chem Toxicol 111:557-566

33. Holland NA, Fraiser CR, Sloan RC, Devlin RB, Brown DA, Wingard CJ (2017) Ultrafine particulate matter increases cardiac ischemia/reperfusion injury via mitochondrial permeability transition pore. Cardiovasc Toxicol 17(4):441-450

34. Tong H, Krug JD, Krantz QT, King C, Hargrove MM, Gilmour MI, Gavett SH (2018) Inhalation of simulated smog atmospheres affects cardiac function in mice. Cardiovasc Toxicol 18(6):569-578 
35. Bossert F, Meyer H, Wehinger E (1981) 4-Aryldihydropyridines, a new class of highly active calcium antagonists. Angewandte Chemie International Edition in English 20(9):762-769

36. Breitenbucher JG, Figliozzi G (2000) Solid-phase synthesis of 4-aryl-1, 4-dihydropyridines via the Hantzsch three component condensation. Tetrahedron Lett 41(22):4311-4315

37. Ferdinandy P, Hausenloy DJ, Heusch G, Baxter GF, Schulz R (2014) Interaction of risk factors, comorbidities, and comedications with ischemia/reperfusion injury and cardioprotection by preconditioning, postconditioning, and remote conditioning. Pharmacological reviews 66(4):11421174

38. Feyzizadeh S, Badalzadeh R (2017) Application of ischemic postconditioning's algorithms in tissues protection: response to methodological gaps in preclinical and clinical studies. J Cell Mol Med 21(10):2257-2267

39. Camara AK, Chen Q, Rhodes SS, Riess ML, Stowe DF (2004) Negative inotropic drugs alter indexes of cytosolic [Ca2+]-left ventricular pressure relationships after ischemia. Am J Physiol Heart Circ Physiol 287(2):H667-H680

40. He L, Hao S, Wang Y, Yang W, Liu L, Chen H, Qian J (2019) Dexmedetomidine preconditioning attenuates ischemia/reperfusion injury in isolated rat hearts with endothelial dysfunction. Biomed Pharmacother 114:108837

41. Billman GE, Hamlin RL (1996) The effects of mibefradil, a novel calcium channel antagonist on ventricular arrhythmias induced by myocardial ischemia and programmed electrical stimulation. J Pharmacol Exp Ther 277(3):1517-1526

42. Song T, Chu X, Zhang X, Song Q, Zhang Y, Zhang Y, ... Chu L (2017) Bufalin, a bufanolide steroid from the parotoid glands of the Chinese toad, inhibits L-type Ca2 + channels and contractility in rat ventricular myocytes. Fundam Clin Pharmacol 31(3):340-346

43. Song Q, Chu X, Zhang X, Bao Y, Zhang Y, Guo H, ... Chu L (2016) Mechanisms underlying the cardioprotective effect of salvianic acid $A$ against isoproterenol-induced myocardial ischemia injury in rats: possible involvement of L-type calcium channels and myocardial contractility. J Ethnopharmacol 189:157-164

44. Singhal AK, Symons JD, Boudina S, Jaishy B, Shiu YT (2010) Role of endothelial cells in myocardial ischemia-reperfusion injury. Vascular disease prevention 7:1

45. Tschudi MR, Criscione L, Novosel D, Pfeiffer K, Lüscher TF (1994) Antihypertensive therapy augments endothelium-dependent relaxations in coronary arteries of spontaneously hypertensive rats. Circulation 89(5):2212-2218

46. Simonovic N, Jeremic J (2017) Role of calcium channel blockers in myocardial preconditioning. Serbian Journal of Experimental Clinical Research 18(4):281-287

47. Huang Z, Li H, Guo F, Jia Q, Zhang Y, Liu X, Shi G (2009) Egr-1, the potential target of calcium channel blockers in cardioprotection with ischemia/reperfusion injury in rats. Cell Physiol Biochem 24(12):17-24 
48. Massoudy P, Becker BF, Seligmann C, Gerlach E (1995) Preischaemic as well as postischaemic application of a calcium antagonist affords cardioprotection in the isolated guinea pig heart. Cardiovascular research 29(4):577-582

49. Tanaka M, Nishimura R, Nishimura T, Kawai T, Meguro S, Irie J, ... \& Itoh H (2014) Effect of single tablet of fixed-dose amlodipine and atorvastatin on blood pressure/lipid control, oxidative stress, and medication adherence in type 2 diabetic patients. Diabetol Metab Syndr 6(1):56

50. Chu SY, Peng F, Wang J, Liu L, Meng L, Zhao J, ... Ding WH (2020) Catestatin in defense of oxidativestress-induced apoptosis: A novel mechanism by activating the beta2 adrenergic receptor and PKB/Akt pathway in ischemic-reperfused myocardium. Peptides 123:170200

51. Necas J, Bartosikova L, Florian T, Klusakova J, Suchý V, Naggar EM, ... \& Lisková M (2006) Protective effects of the flavonoids osajin and pomiferin on heart ischemia-reperfusion. Ceska a Slovenska farmacie: casopis Ceske farmaceuticke spolecnosti a Slovenske farmaceuticke spolecnosti 55(4):168-174

52. Alam M, Singh BK, Kumar V (2015) Amlodipine potentiates the protective effect of zonisamide on pentylenetetrazol-induced kindling in mice. Drug Development Therapeutics 6(2):88

53. Sugawara H, Tobise K, Kikuchi K (1996) Antioxidant effects of calcium antagonists on rat myocardial membrane lipid peroxidation. Hypertens Res 19(4):223-228

54. Komolafe K, Akinmoladun AC, Olaleye MT (2013) Methanolic leaf extract of Parkia biglobosa protects against doxorubicin-induced cardiotoxicity in rats. International journal of applied research in natural products $6(3): 39-47$

55. Carosati E, loan P, Micucci M, Broccatelli F, Cruciani G, Zhorov BS, ... Budriesi R (2012) 1, 4Dihydropyridine scaffold in medicinal chemistry, the story so far and perspectives (part 2): action in other targets and antitargets. Curr Med Chem 19(25):4306-4323

56. Fontecha-Tarazona HD, Brinkerhoff RC, de Oliveira PM, Rosa SB, Flores DC, D'Oca, C. D. R. M., ... \& D'Oca MM (2015) Multicomponent synthesis of novel hybrid PHQ-fatty acids. RSC Advances 5(73):59638-59647

57. Núñez-Vergara LJ, Santander P, Navarrete-Encina PA, Squella JA (2005) Electrochemical reduction of C-4 nitrosophenyl 1, 4-dihydropyridines and their parent C-4 nitrophenyl derivatives in protic media. Journal of electroanalytical chemistry 580(1):135-144

58. limura O, Shimamoto K (1993) Efficacy and mode of action of manidipine: a new calcium antagonist. American heart journal 125(2):635-641

59. Kwong JQ (2017) The mitochondrial calcium uniporter in the heart: energetics and beyond. J Physiol 595(12):3743-3751

60. Kurhanewicz N, McIntosh-Kastrinsky R, Tong H, Walsh L, Farraj AK, Hazari MS (2014) Ozone coexposure modifies cardiac responses to fine and ultrafine ambient particulate matter in mice: concordance of electrocardiogram and mechanical responses. Part Fibre Toxicol 11(1):54

\section{Figures}


<smiles>CC1=C(C(=O)OCc2ccccc2)C(c2ccccc2[N+](=O)[O-])C(C(=O)OCc2ccccc2)=C(C)N1</smiles>

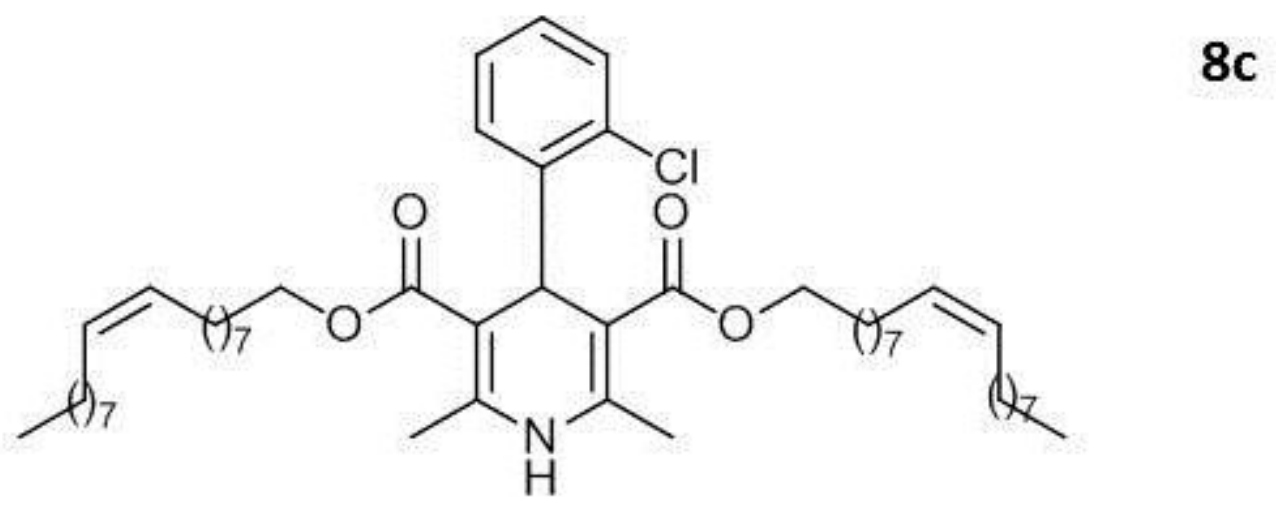<smiles>CCCCOC(=O)C1=C(C)NC(C)=C(C(=O)OCC)C1c1ccc(Cl)cc1</smiles>

Figure 1

Schematic images of fatty dihydropyridines tested in this study $[12,18,19]$. 


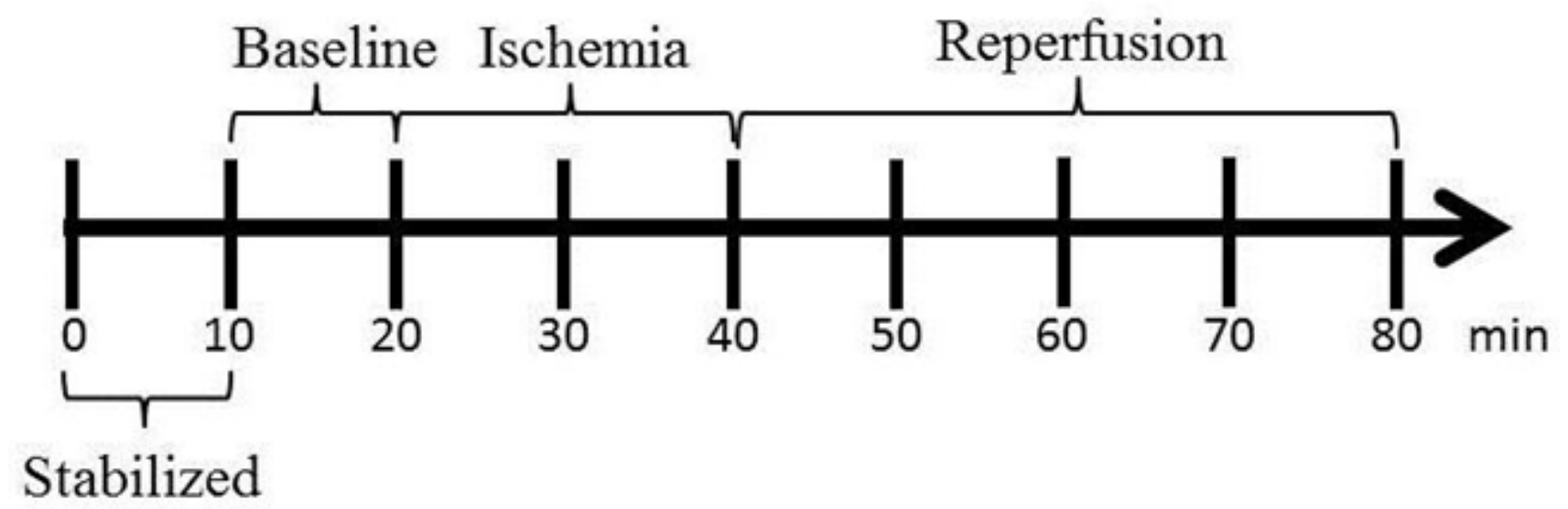

Figure 2

Schematic illustration of the experimental protocol for ischemia and reperfusion in isolated hearts. 


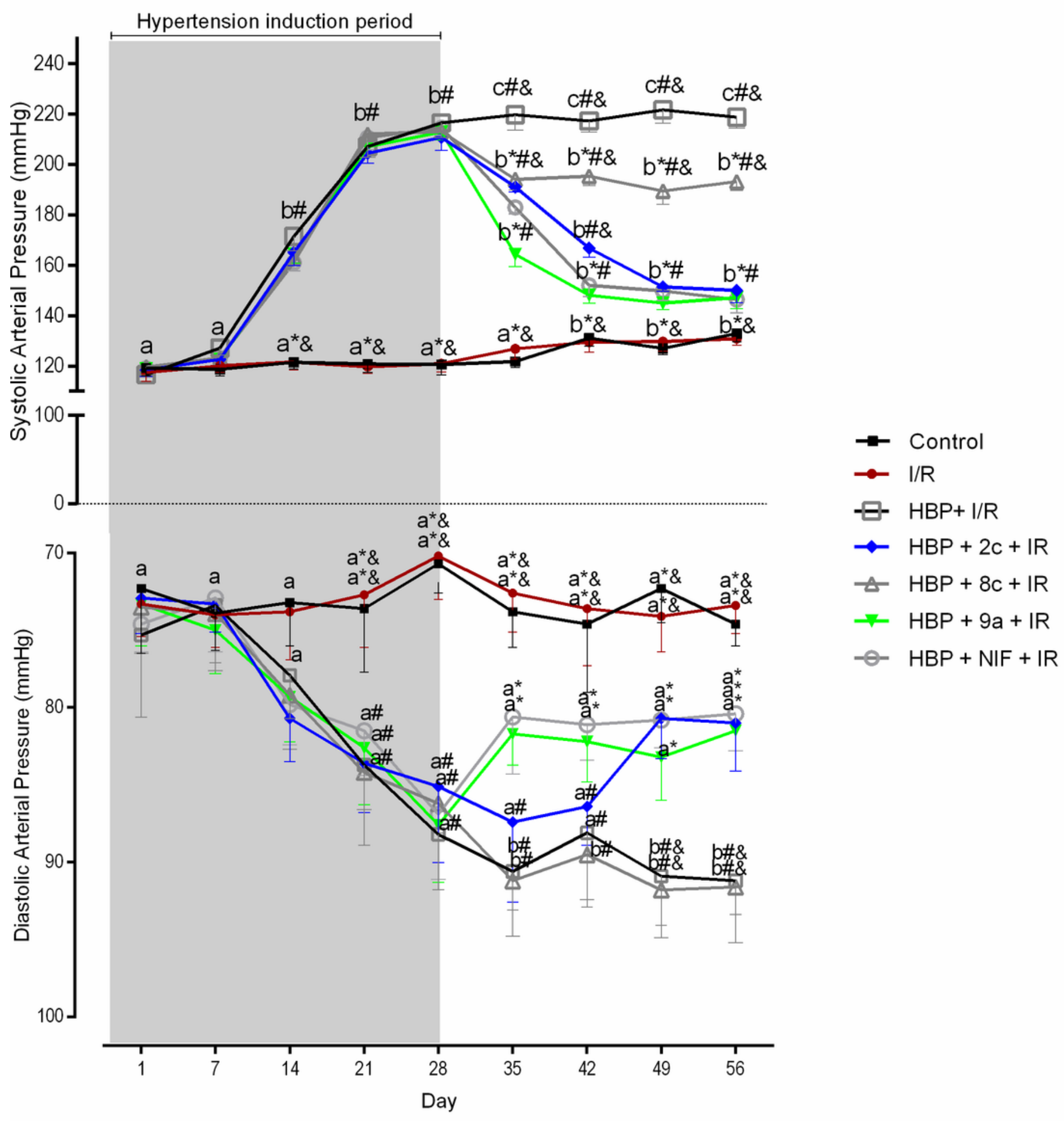

Figure 3

Blood pressure was monitored throughout the experiment. For 28 days, a high blood pressure induction was performed, from day 28 to day 56 of animals that received treatments or saline solution (Control, I/R and HBP $+\mathrm{I} / \mathrm{R}$ ). Data are shown as mean and SEM. The * symbol represents the statistical difference between the group High blood pressure and ischemia and reperfusion (HBP $+\mathrm{l} / \mathrm{R}$ ) vs all other groups. The \# symbol represents the statistical difference between the Control group versus all other groups. The \& 
symbol represents the statistical difference between High blood pressure treated with nifedipine after the ischemia and reperfusion group ( $\mathrm{HBP}+\mathrm{NIF}+\mathrm{I} / \mathrm{R}$ ) versus all other groups. Different letters represent statistically significant differences among the times of the same group.
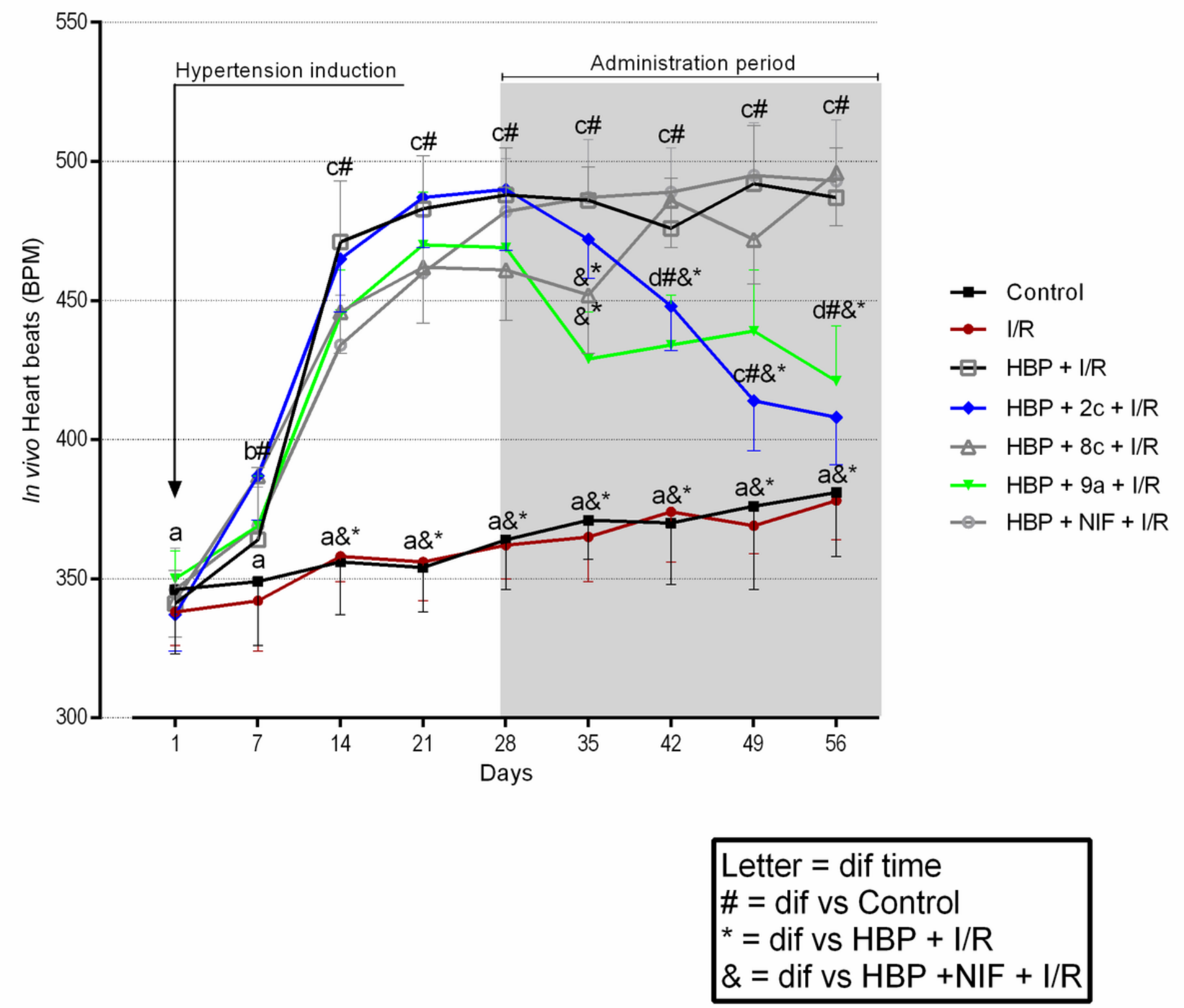

\section{Figure 4}

The heart rate was monitored throughout of the experiment. For 28 days, a high blood pressure induction was performed, from day 28 to day 56 of animals that received treatments or saline solution (Control, I/R and HBP $+\mathrm{I} / \mathrm{R}$ ). Data are shown as mean and SEM. The * symbol represents the statistical difference between the group High blood pressure and ischemia and reperfusion (HBP $+\mathrm{l} / \mathrm{R}$ ) vs all other groups. The \# symbol represents the statistical difference between the Control group versus all other groups. The \& symbol represents the statistical difference between High blood pressure treated with nifedipine after the 
ischemia and reperfusion group ( $\mathrm{HBP}+\mathrm{NIF}+\mathrm{I} / \mathrm{R})$ versus all other groups. Different letters represent statistically significant differences among times of the same group.

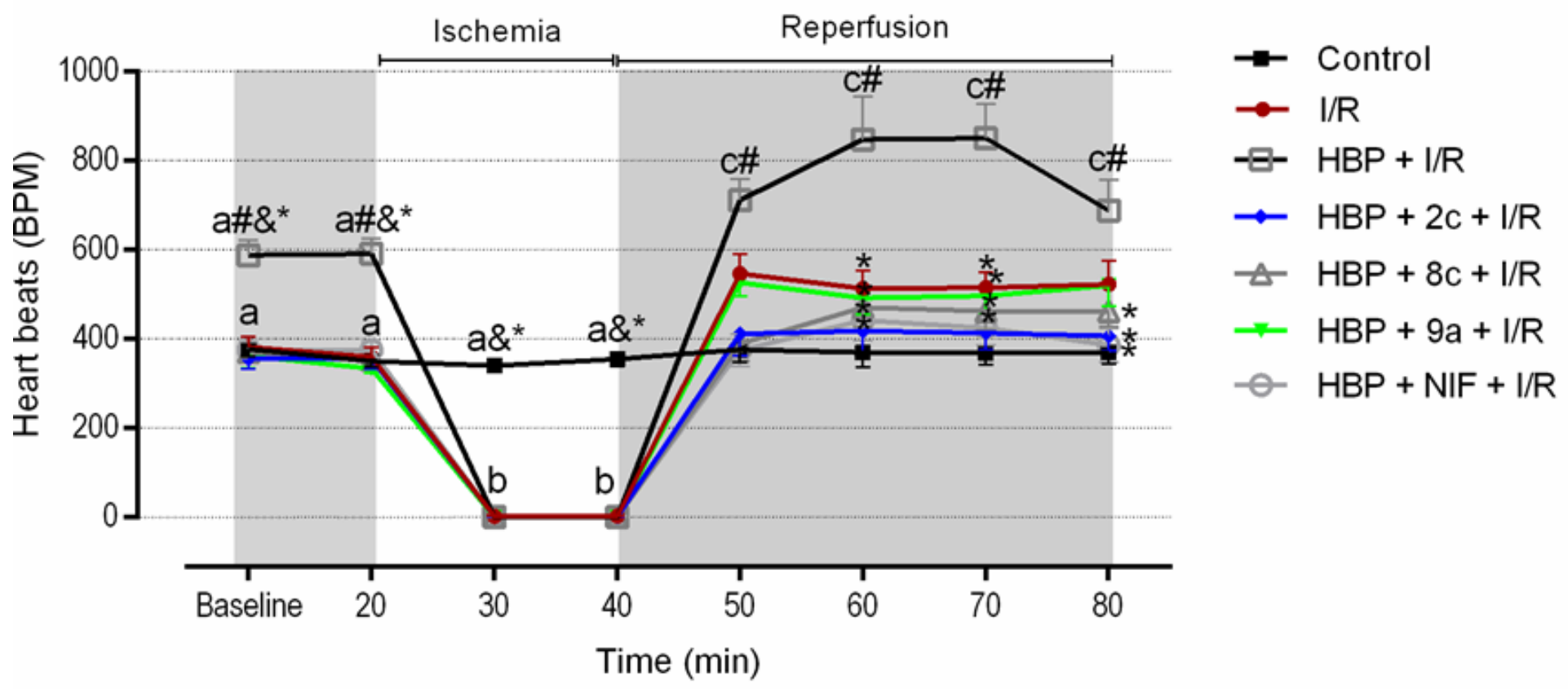

Figure 5

Heart rate measured in beats per minute (BPM) in the isolated heart. The baseline (10 minutes) corresponds to the normal period after 10 minutes of stabilization, after ischemia (20 minutes) and reperfusion (40 minutes). Data are shown as mean and SEM. The * symbol represents the statistical difference between the group High blood pressure and ischemia and reperfusion (HBP $+\mathrm{I} / \mathrm{R}$ ) vs all other groups. The \# symbol represents the statistical difference between the Control group versus all other groups. The \& symbol represents the statistical difference between High blood pressure treated with nifedipine after ischemia and reperfusion group $(\mathrm{HBP}+\mathrm{NIF}+\mathrm{I} / \mathrm{R})$ versus all other groups. Different letters represent statistically significant differences among the times of the same group. 


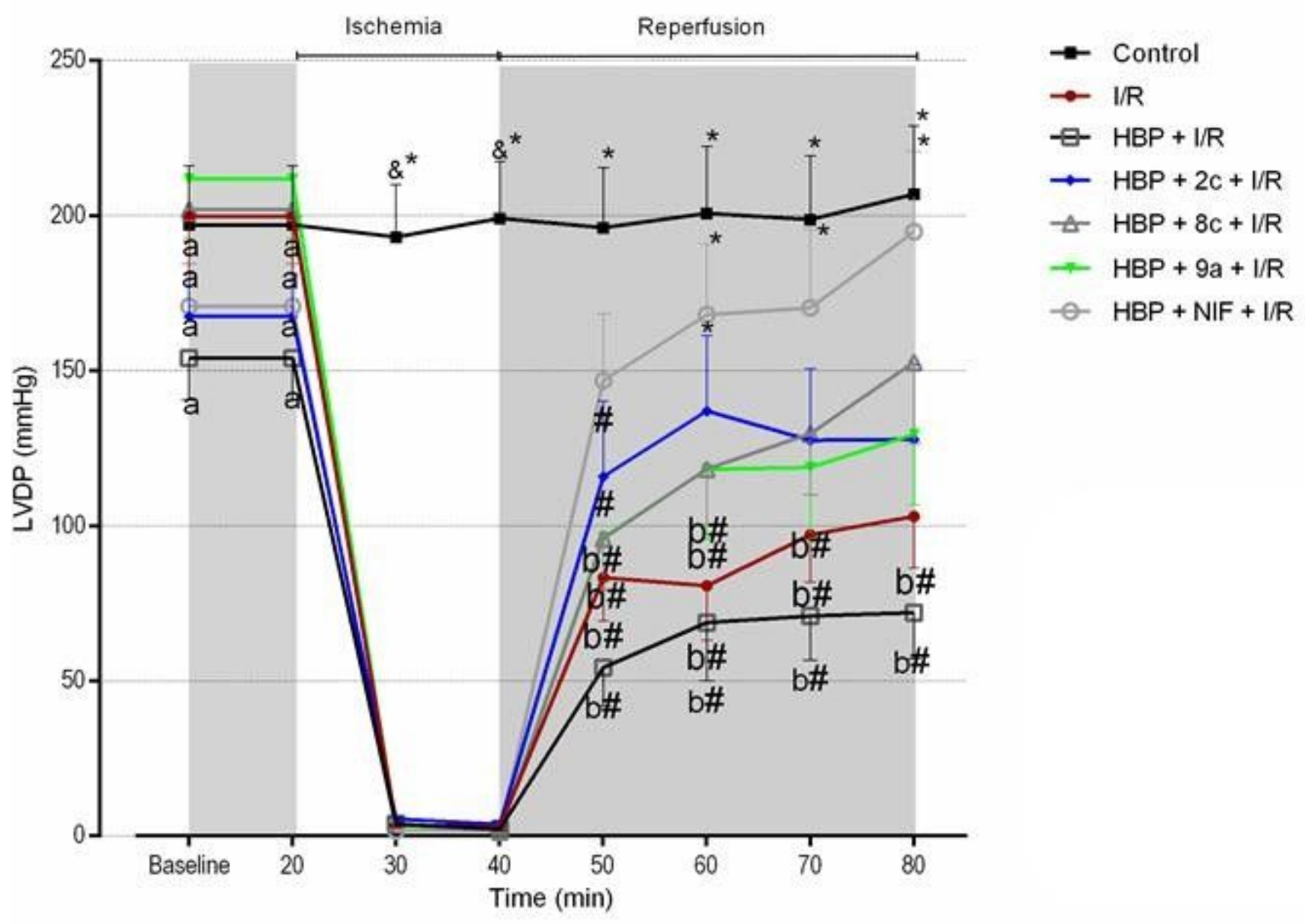

Figure 6

LVDP (in $\mathrm{mmHg}$ ) evaluation over the experiment time. The baseline (10 minutes) corresponds to the normal period after 10 minutes of stabilization, followed by ischemia (20 minutes) and reperfusion (40 minutes). Data are shown as mean and SEM. The * symbol represents the statistical difference between the group High blood pressure and ischemia and reperfusion (HBP $+\mathrm{I} / \mathrm{R})$ vs all other groups. The \# symbol represents the statistical difference between the Control group versus all other groups. The \& symbol represents the statistical difference between High blood pressure treated with nifedipine after ischemia and reperfusion group ( $\mathrm{HBP}+\mathrm{NIF}+\mathrm{I} / \mathrm{R})$ versus all other groups. Different letters represent statistically significant differences among the times of the same group. 
A

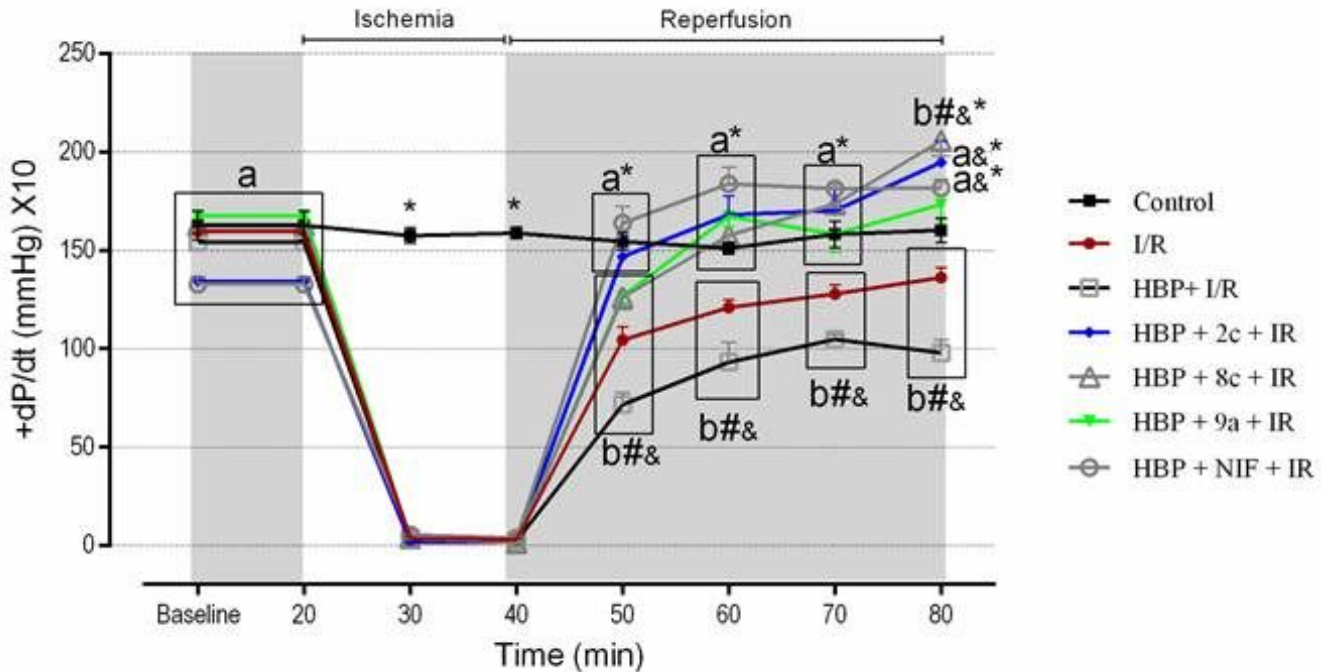

B

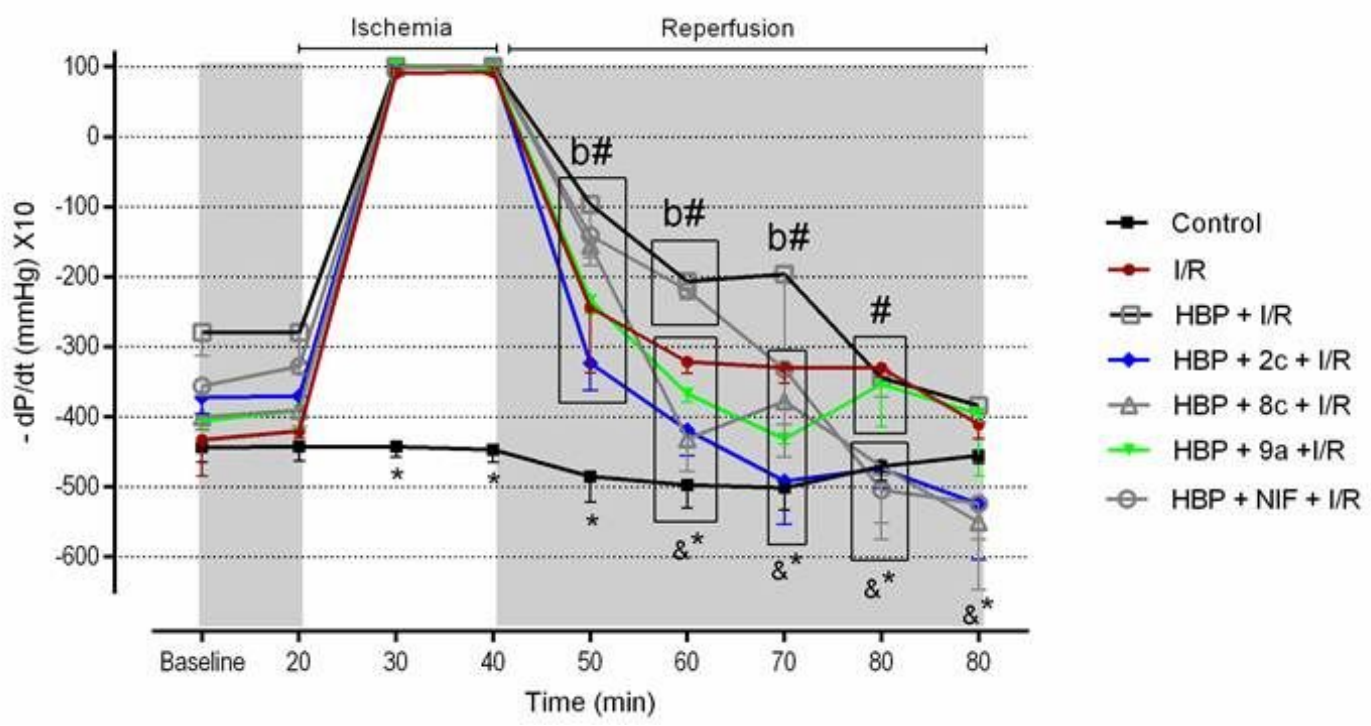

Figure 7

Pressure derivative/time derivative for ventricular ejection fraction and ventricular relaxation $( \pm \mathrm{dP} / \mathrm{dT}$ in $\mathrm{mmHg}$ ) obtained by the angular coefficient of the cardiac functionality line, evaluated over the experiment time and expressed in mean and SEM. The baseline (10 minutes) corresponds to the normal period after 10 minutes of stabilization, after ischemia (20 minutes) and reperfusion (40 minutes). Data are shown as mean and SEM. The * symbol represents the statistical difference between the group High blood pressure and ischemia and reperfusion (HBP + I/R) vs all other groups. The \# symbol represents the statistical difference between the Control group versus all other groups. The \& symbol represents the statistical difference between High blood pressure treated with nifedipine after ischemia and reperfusion group (HBP + NIF + I/R) versus all other groups. Different letters represent statistically significant differences among the times of the same group. 


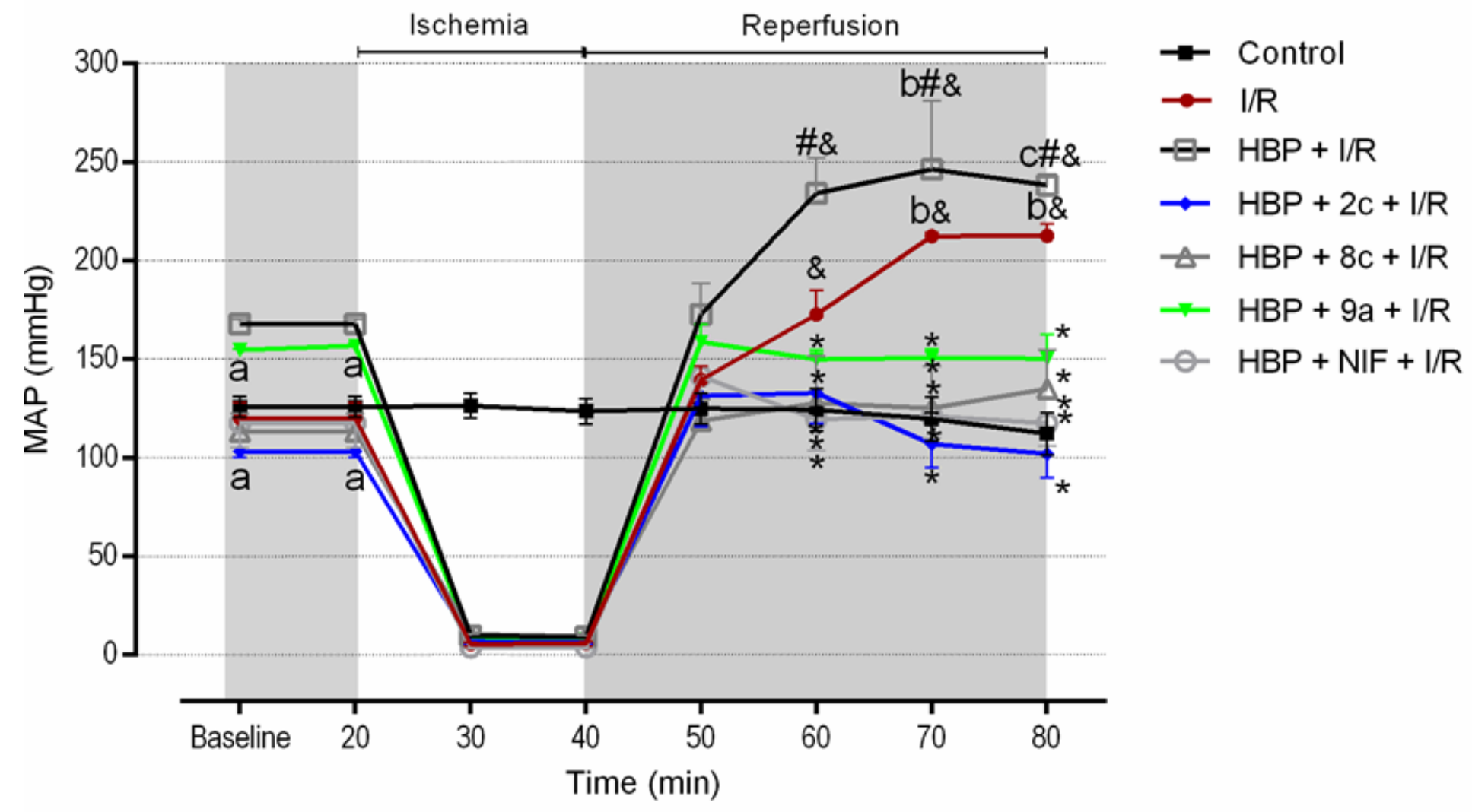

Figure 8

Mean arterial pressure (in $\mathrm{mmHg}$ ) evaluated over the experiment time. The baseline (10 minutes) corresponds to the normal period after 10 minutes of stabilization, after ischemia (20 minutes) and reperfusion (40 minutes). Data are shown as mean and SEM. The * symbol represents the statistical difference between the group High blood pressure and ischemia and reperfusion (HBP $+\mathrm{I} / \mathrm{R})$ vs all other groups. The \# symbol represents the statistical difference between the Control group versus all other groups. The \& symbol represents the statistical difference between High blood pressure treated with nifedipine after ischemia and reperfusion group $(\mathrm{HBP}+\mathrm{NIF}+\mathrm{I} / \mathrm{R})$ versus all other groups. Different letters represent statistically significant differences among the times of the same group. 


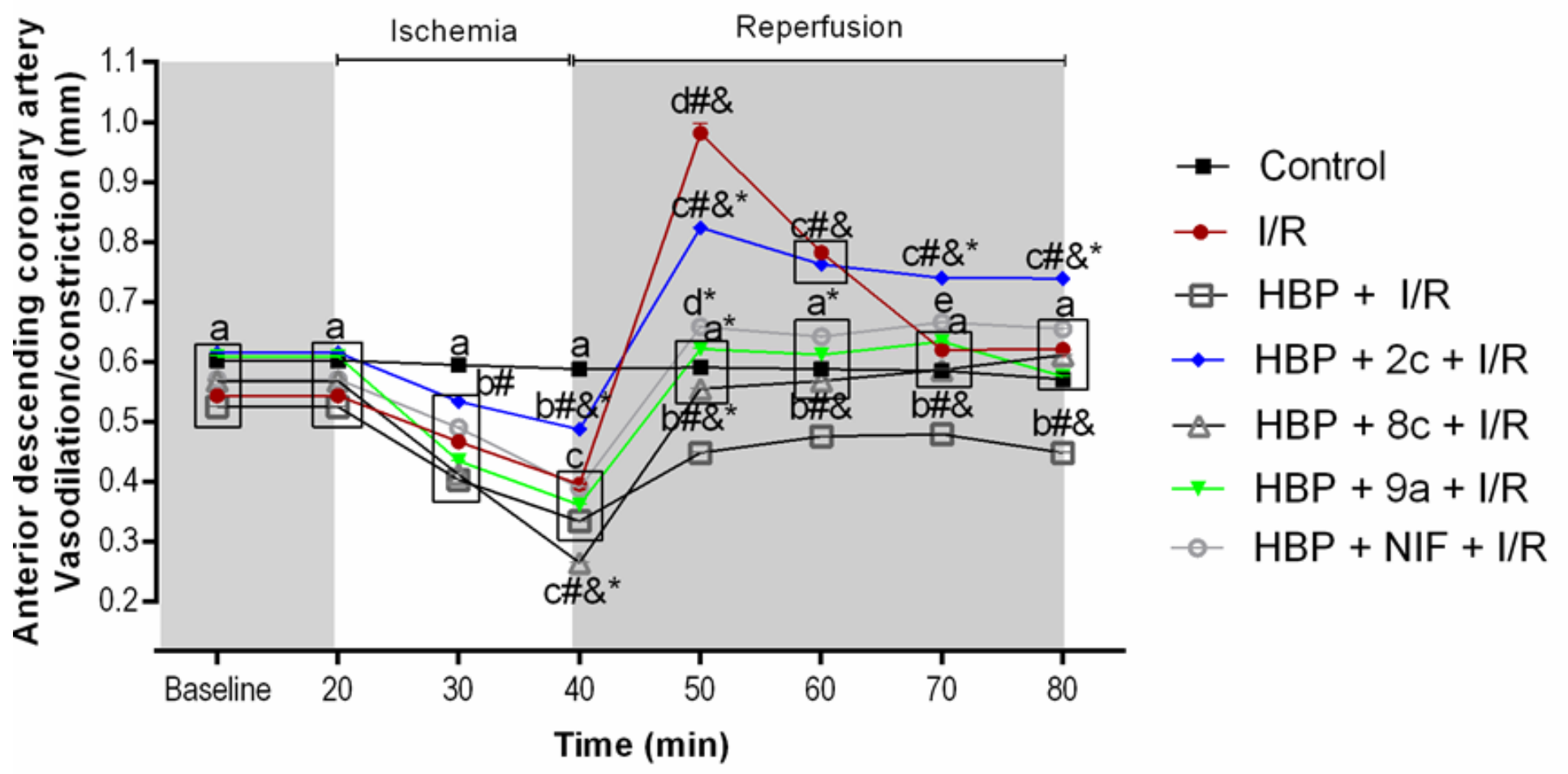

Figure 9

Measurement of the degree of constriction of the left anterior descending coronary artery (in $\mathrm{mm}$ ) evaluated over the experiment time. The baseline (10 minutes) corresponds to the normal period after 10 minutes of stabilization, after ischemia (20 minutes) and reperfusion (40 minutes). Data are shown as mean and SEM. The * symbol represents the statistical difference between the group High blood pressure and ischemia and reperfusion (HBP $+\mathrm{I} / \mathrm{R}$ ) vs all other groups. The \# symbol represents the statistical difference between the Control group versus all other groups. The \& symbol represents the statistical difference between High blood pressure treated with nifedipine after ischemia and reperfusion group $(\mathrm{HBP}+\mathrm{NIF}+\mathrm{l} / \mathrm{R})$ versus all other groups. Different letters represent statistically significant differences among the times of the same group. 


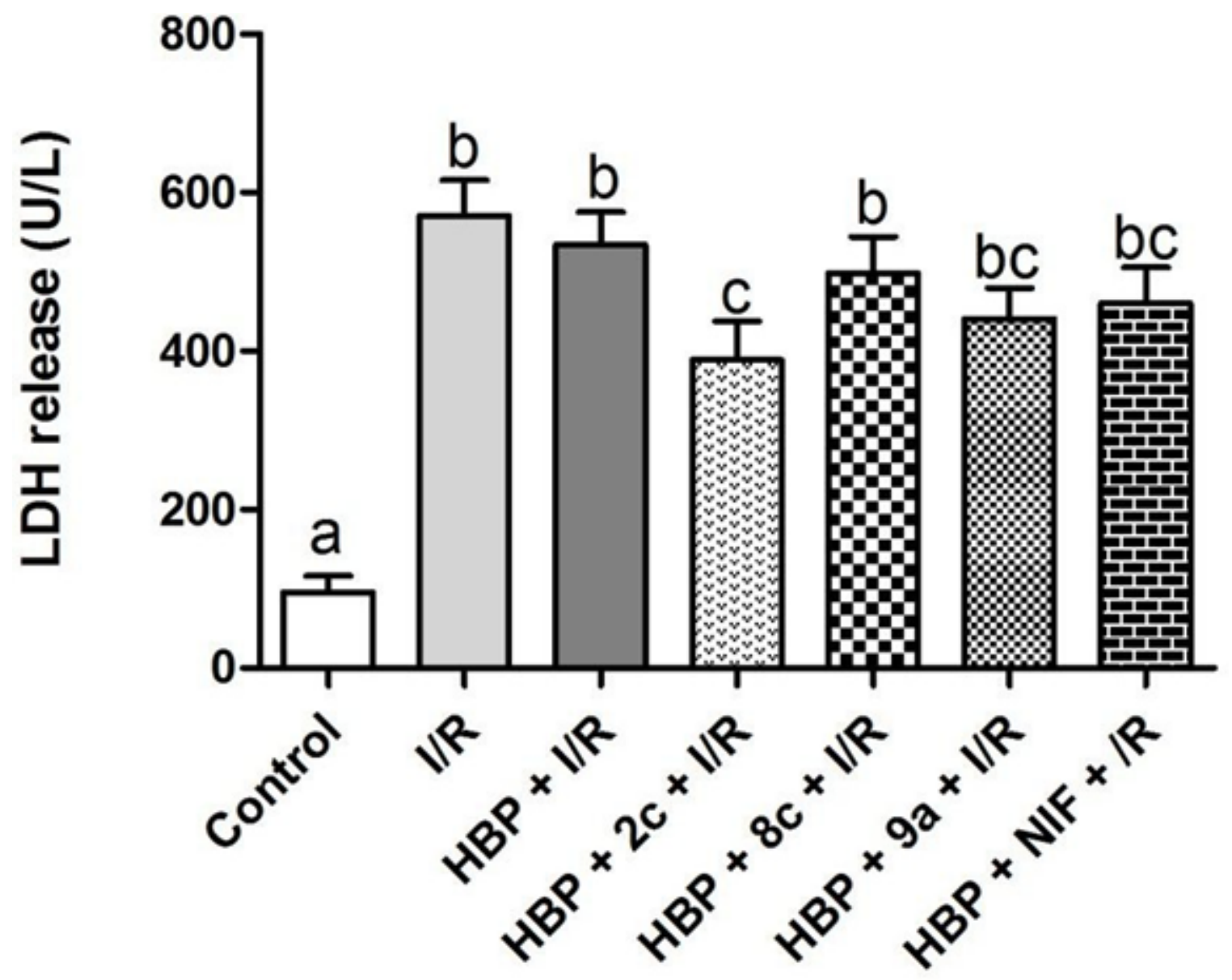

Figure 10

Lactate dehydrogenase values analyzed from perfusate after ischemia and reperfusion in time of 80 minutes. Values are means \pm SEM. Different letters indicate a difference $(p<0.05)$ between groups. 


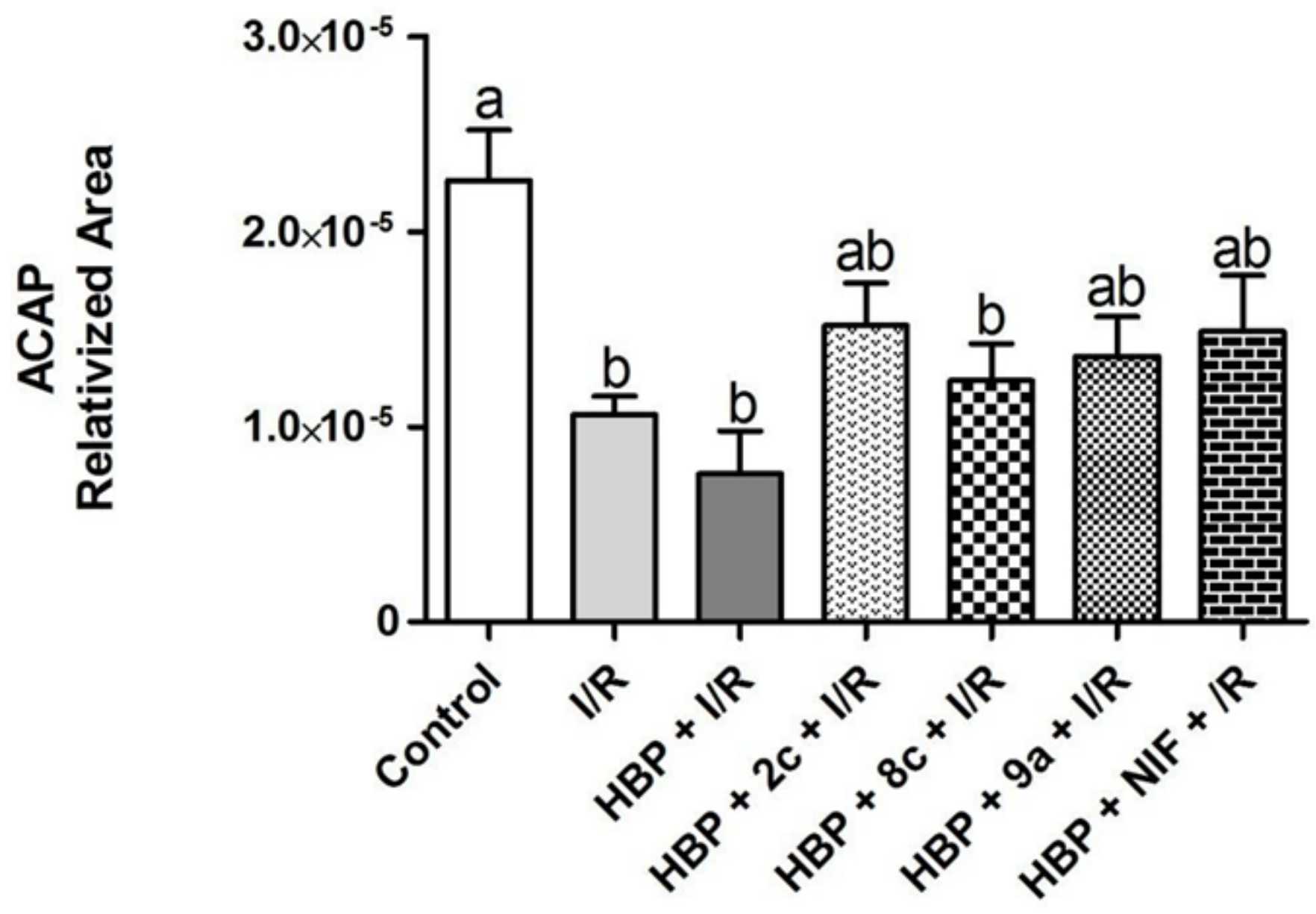

Figure 11

Total antioxidant capacity values analyzed from cardiac tissue after ischemia and reperfusion. Values are mean \pm SEM and the different letters indicate statistical difference $(p<0.05)$ between the groups. 


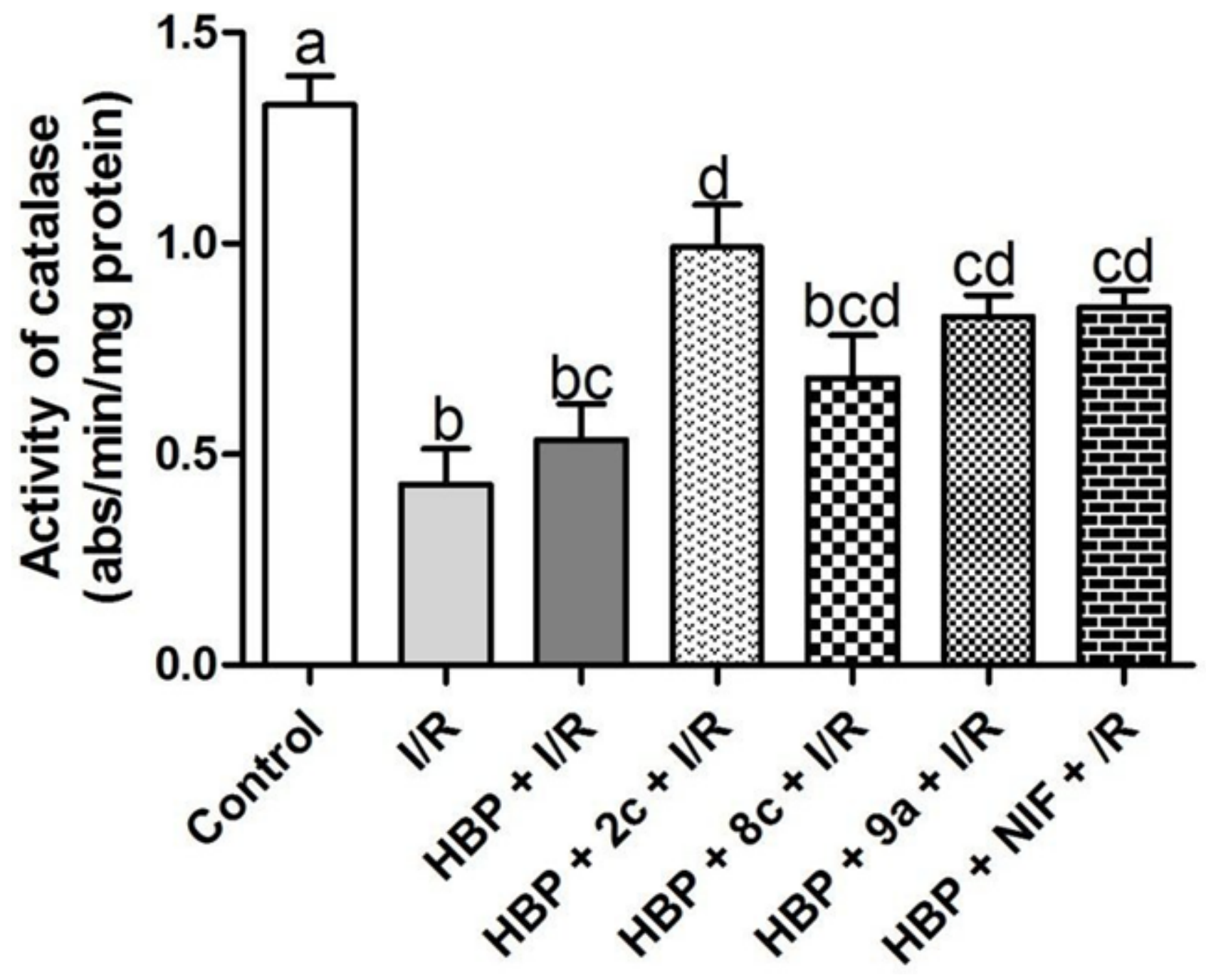

Figure 12

Catalase activity analyzed in cardiac tissue after ischemia and reperfusion. Values are mean \pm SEM and the different letters indicate statistical difference $(p<0.05)$ between the groups. 


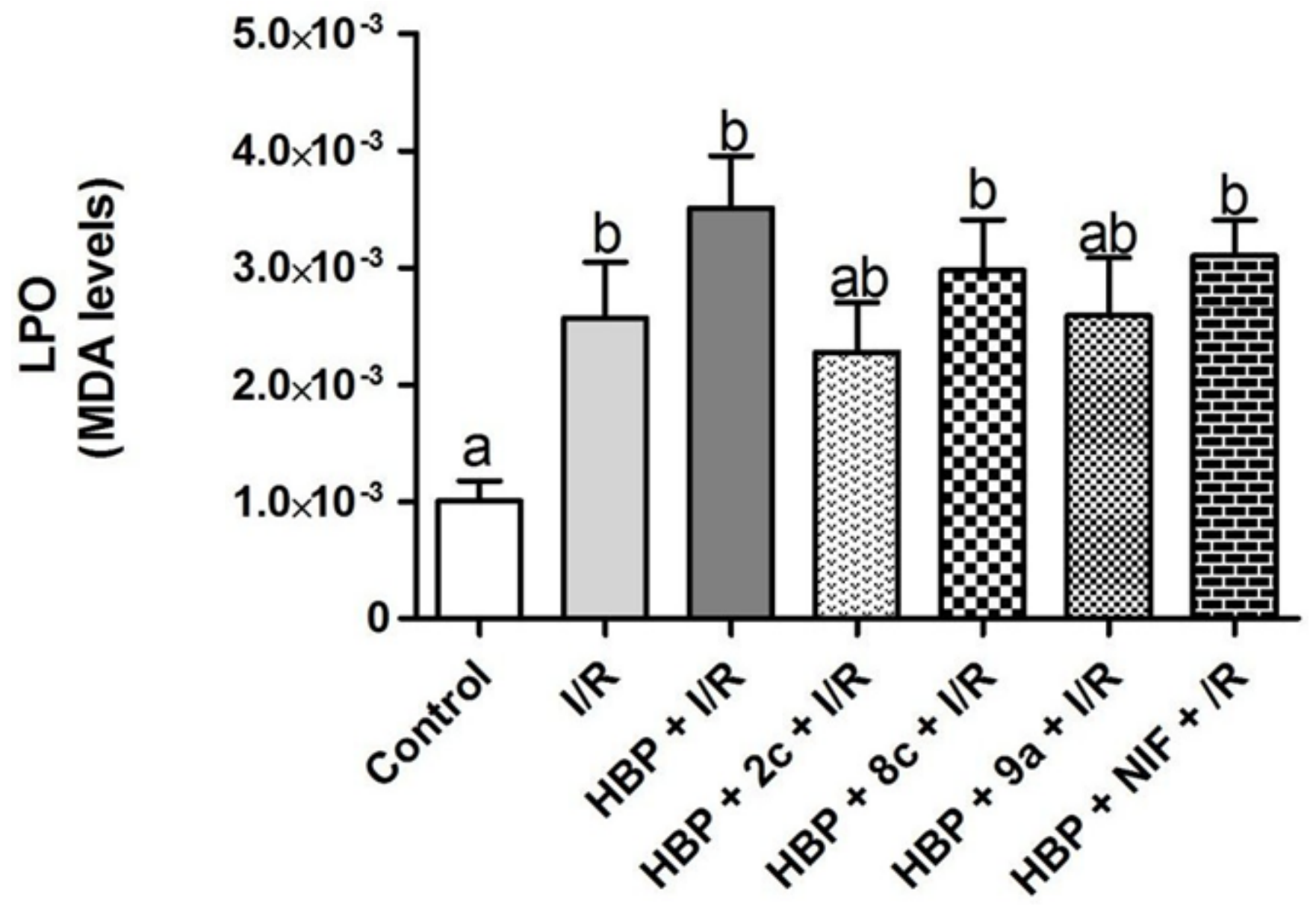

Figure 13

The values of lipid peroxidation analyzed from cardiac tissue after ischemia and reperfusion. Values are mean \pm SEM, and the different letters indicate statistical difference $(p<0.05)$ between the groups.

\section{Supplementary Files}

This is a list of supplementary files associated with this preprint. Click to download.

- SupplementarydataSantaHelena.docx 